\title{
TRAZAS PARA IRIA FLAVIA
}

\author{
POR \\ MIGUEL TAÍN GUZMÁN \\ Profesor de Historia del Arte de la Universidad de Santiago de Compostela
}

\begin{abstract}
The current urban and monumental configuration of Iria Flavia-Roman foundation, dependent on its Administration of Padron, epischopal seat until its transfer to Santiago de Compostela after the discovery of the Apostle's tomb- is the result of the constructive and artistic activity in XVII and XVIII centuries. From that time are the current Colegiata of Santa María and the Casa de los Canónigos («Canon's Place»), in front of the church, on the other side of the way which joins Pontevedra with Santiago. Many reputated architects and masters on such works were required, coming from the neighbouring Compostela, in order to construct this two emblematic buildings. The same happened with the furniture- altarpiece, Chorus chairs, etc.- carried out by important and well-known compostelan carvers, introducing, finally, the Baroque and Neoclasicism in Iria. Such an innovation implied plenty plans and designs, some of them signed by important artists of the Galician art. Some of them arrived to us and are studied on the following pages.
\end{abstract}

\section{LOS PROYECTOS PARA REFORMAR LA COLEGIATA}

A finales del siglo xvir la colegiata, construida en el siglo xiII, presentaba una planta de cruz latina con cuerpo basilical de tres naves, la central más desarrollada, crucero que no sobresalía en planta y cabecera de tres ábsides semicirculares ${ }^{~}$. Aprovechando la existencia de arbotantes, un pórtico o logia rodeaba exteriormente el cuerpo de las naves en forma de U. Adosada al brazo sur del crucero se encontraba la capilla subsistente de San Ildefonso construida en 1666 por el arquitecto trasmerano Melchor de Velasco, respondiendo a la fundación de Alonso de la Peña Montenegro, obispo de Quito, natural de Padrón y antiguo canónigo de Iria ${ }^{2}$.

La amenaza de ruina hizo que el cabildo iriense, el ayuntamiento de Padrón y Francisco Sanmamed y Montaos, patrono de la citada fundación, organizaran un concurso abierto a todos los arquitectos del Reino para que expusiesen sus proyectos de reconstrucción y reestruc-

1 Sobre el antiguo templo véanse Zepedano y Carnero, J.M. ${ }^{a}$, Historia y descripción arqueológica de la Basílica Compostelana, Lugo, 1870, 58-68; Murguía, M., Galicia, Barcelona, 1981 (1. a ed. 1888), 610-614; Rodríguez González, A., «El Codex Historicus - Historia de Iria- de la biblioteca del Consulado de La Coruña», Cuadernos de Estudios Gallegos, 1953, 65-85; Idem, «La Iglesia de Iria en el siglo XvI», Compostellanum, 1963, 229-300; Chamoso Lamas, M., «Lugares santos jacobeos: Iria Flavia, Padrón y Compostela», Santiago en España, Europa y América, Madrid, 1971, 39-42; Idem, «Noticia sobre la importancia arqueológica de Iria Flavia (Padrón-La Coruña)», Archivo Español de Arqueología, 1974, 125-137; Idem, «Iria Flavia, Santa María de», Gran Enciclopedia Gallega, Santiago-Gijón, 42-45.

${ }^{2}$ Cfr. Bonet Correa, A., La arquitectura en Galicia durante el siglo xvII, Madrid, 1984 (2. ${ }^{a}$ ed.), 322. La capilla neoclásica que hoy prolonga el brazo norte del crucero, dedicada a la Virgen de Belén, fue construida tiempo después. 
turación del viejo edificio ${ }^{3}$. El 26 de marzo de 1689, reunido el consistorio padronés en la Casa del Ayuntamiento, se presenta Diego de Romay «maestro llamado para el reconoçimiento de la ygleçia..., y dijo que, auiendolo echo» ${ }^{4}$, recomienda la reconstrucción de la capilla mayor medieval semicircular y el reforzamiento de las paredes laterales de las naves, añadiendo unos estribos «a modo de pilastres» a la altura de los contrafuertes exteriores que sustentan el peso de la cubierta ${ }^{5}$. Asimismo propone que se aproveche la ocasión tanto para construir un nuevo abovedamiento a las tres naves, renovando los arcos y disponiendo como soporte pilastras adosadas a los antiguos pilares medievales, como para horadar ventanas que permitan una correcta iluminación del interior. Valora el total de la intervención en 93.738 reales ${ }^{6}$.

En otro documento afirma que el modelo que sigue en su propuesta es la iglesia de la Compañía de Santiago, cuyo cuerpo de tres naves con tribuna, coro y fachada occidental fueron construidos por él mismo entre los años 1679 y $1673^{7}$. Así, declara que en sus condiciones va implícita la existencia de «... capillas bajas y altas como [en] la yglesia de la Conpañia, de modo que por las claraboyas altas se puede andar y la de abajo siruen de capillas cada una distinta con pilastrones que sobresalen como estribos y siruen de resebir las bobedas, y juntamente forman capillas a los costados del cuerpo de la yglesia, con que biene a ser obra de mas consequencia por ser dobladas las bobedas altas y bajas, porque se puede andar por ensima de las capillas y coro» ${ }^{8}$.

El ayuntamiento apreció en su momento el informe y la planta que lo acompañaba, hoy perdida, remunerando al artífice con 150 reales. Pero, dado que la decisión final dependía del dictamen de las otras dos entidades afectadas, decidieron que de la declaración técnica del ar-

\footnotetext{
3 Archivo Histórico Universitario de Santiago (A.H.U.S.), Sección Ayuntamiento de Santiago, Libro 717, Varia, t. II, 1563-1698, doc. 42 (la documentación de la subasta ha sido publicada por Taín Guzmán, M., Los arquitectos y la contratación de obra arquitectónica en la Galicia Barroca (1650-1700), Sada, 1997, pp. 159-173.

${ }^{4}$ Romay ya era conocido del consistorio, pues diez años antes había ajustado con él el retablo mayor de la iglesia de Santiago de Padrón. Archivo Municipal de Padrón (A.M.P.), Actas Consistoriales de Padrón, Caja n. ${ }^{\circ}$, Año 1679, fols. 13v., 14v., 16r.v., 17r. y 31r., Año 1680, fols. 34v., 38r.-39r., 40r.-48r. y 49r.v. Para una visión general de la biografía y obras de este artista véanse Murguía, M., El Arte en Santiago durante el siglo xvin y noticia de los artistas que florecieron en dicha ciudad y centuria, Madrid, 1884, 229; Pérez Costanti, P., Diccionario de artistas que florecieron en Galicia durante los siglos XVI y XVII, Santiago, 1930, 485-487; Couselo Bouzas, J., Galicia artística en el siglo XVIII y primer tercio del xIX, Compostela, 1932, 589; Bonet Correa, A., «Un soneto sobre Diego de Romay», Cuadernos de Estudios Gallegos, 1957,

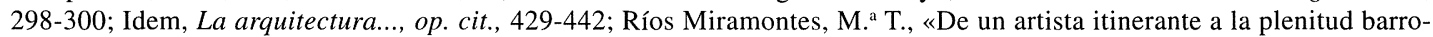
ca de Diego de Romay. La Capilla del Rosario de la iglesia parroquial de Villagarcía (Pontevedra)», VI Congreso Español de Historia del Arte, CEHA, Los Caminos y el arte, t. II, El arte en los Caminos, 1989, 259-269; Fernández Gasalla, L., Aportación documental sobre a actividade artística compostelana entre 1649 e 1686, Tesis de Licenciatura inédita, Santiago, 1991; Idem, «El Pazo de Santa Cruz de Rivadulla y el mecenazgo de la familia Mondragón», Abrente, 1992, 3-27; Idem, «Las bibliotecas de los arquitectos gallegos en el siglo xvir: los ejemplos de Francisco Dantas y Diego de Romay», Museo de Pontevedra, 1992, 327-355; García Iglesias, J.M., El Barroco (I), La época. Los patrocinadores. Arquitectos del siglo XVII, Galicia, Arte, t. XIII, A Coruña, 1993, 377-399; Idem, «Diego de Romay, arquitecto barroco gallego», Tiempo y espacio en el arte, Homenaje al profesor Antonio Bonet Correa, Universidad Complutense de Madrid, Anales de Historia del Arte, Número extraordinario, 1994, t. I, 577-591; Fernánez Álvarez, M. ${ }^{a}$ A., Arte y sociedad en Compostela 1660-1710, Sada, 1996.

${ }^{5}$ El artista había llegado a Iria dos días antes, el 24 de marzo. El 25 ya informa al consistorio de que está «formando vna memoria de advertencias de lo en que consiste la obra y reparos de la yglesia y, acabando, la entregara al... scriuano». A.M.P., Actas Consistoriales de Padrón, Caja 5, 1689, fol. $21 \mathrm{v}$.

6 A.M.P., Actas Consistoriales de Padrón, Caja 5, 1689, fols. 22v.-23v.; A.H.U.S., Sección Ayuntamiento de Santiago, Libro 717, Varia, t. II, 1563-1698, doc. 42 (cfr. Taín Guzmán, M., Los arquitectos..., op. cit., 159-162); véase el Documento 1 del Apéndice Documental. Para la financiación de la obra se organiza un censo (A.M.P., Actas Consistoriales de Padrón, Caja 5, 1689, fols. 40r., 42r., 43r., 44r., 45r., 46r. y 61v.).

Salvo indicación expresa, todas las cantidades son en moneda de vellón.

7 Cfr. Otero Túñez, R., El «legado» artístico de la Compañía de Jesús a la Universidad de Santiago, Santiago, 1986, 27-28. Sobre el origen de tal tipo de planta en el ámbito gallego véanse Bonet Correa, A., La arquitectura..., op. cit., 5156; Vigo Trasancos, A., «La imagen del templo barroco: tradición y renovación», Semata, Las religiones en la historia de Galicia, n. ${ }^{\circ} 7-8,1996,455-456$.

8 A.H.U.S., Sección Ayuntamiento de Santiago, Libro 717, Varia, t. II, 1563-1698, doc. 42, fol. 101r.; Taín Guzmán, M., Los arquitectos..., op. cit., 167-168.
} 
tista «... se saquen dos copias autenticas y vna entregue el señor procurador general, con asistençia del presente scribano, al señor canonigo vicario de la Coligiata desta uilla para que conferida con los señores capitulares de su cauildo resuelban lo que les pareçiere conveniente, y la otra se entregue al señor alcalde mas antiguo para que la remita o entregue al señor Don Francisco Sanmamed y Montaos, actual patron de las obras del ylustrisimo señor obispo de Quito, para que se sirua ansimesmo resoluer lo mas conbeniente». Además, les informa que su opinión «... hes que primero y ante todas [las] cosas se frabique el altar mayor.. que pareçe tendran de coste veynte mill quinientos y setenta y ocho reales» y que tal obra y su presupuesto «se publiquen... para que si vbiere quien baje la postura echa por el maestro se le admita, dando fianças del seguro y cumplimiento de dicha obra» ${ }^{9}$.

En las semanas siguientes se decide que tanto el cabildo de la colegiata como el consistorio nombren cada uno un delegado, para que juntos se encarguen de los trámites previos a la adjudicación de la empresa. Así, el primero designa al canónigo fabriquero Antonio Mariño ${ }^{10}$ y el segundo, el 5 de abril, al regidor Francisco Grande ${ }^{11}$. El 6 de septiembre reciben la postu$r a$ de otro de los grandes arquitectos del barroco gallego, el monje benedictino Fray Gabriel de Casas ${ }^{12}$. En el informe que redacta, después de haber «visto la Yglessia de Santa Maria Diria y reconoçido las ruinas de la bobeda, paredes y arcos», sugiere que la reconstrucción respete en mayor medida la colegiata medieval. Así, mantiene la antigua cabecera, ya descrita, constituida por tres ábsides semicirculares. Como ya había expuesto Romay, según él, es necesario intervenir en el ábside central, donde únicamente se debe demoler el abovedamiento y sustituirlo por uno nuevo «y a la pared sobre que se elige haçerle dos estribos fuertes». También se compromete a que, una vez terminada la obra, dejará el antiguo retablo y la reja «en su lugar». En el ábside de la derecha, sede de la capilla de San Martín, se ha de tirar «la pared del espejo que esta sobre dicha capilla y bolberla a haçer, subiendole el espejo mas alto para que no quede cuuierto por el texado». En el crucero, propone cubrir los tres tramos con bóvedas de arista, así como rehacer varios arcos y estribos. En la nave central opina que se debe deshacer y volver a construir todos los arcos formeros — «los quales son seys, tres de cada lado»- y una línea corrida de imposta que reciba el nuevo abovedamiento de cañón. También quiere reformar toda la cubierta en las naves laterales, construyendo con cantería bóvedas de arista. Resuelve el problema de su iluminación abriendo seis ventanas, una en cada tramo, las cuales «han de ser rasgadas por dentro y fuera, con sus vidrieras y red». En total, valora su intervención en 88.740 reales, es decir, bastante menos dinero que en el presupuesto ya visto y, además, incorporando, «... a la declaraçion del maestro Diego de Romay la obra de las tres bobedas del crucero, parte esencial de la obra, y añadiendo las siete bentanas con sus vidrieras y lo neçessario para el texado», pero suprimiendo la tribuna alta y los ventanales de la nave central ${ }^{13}$.

\footnotetext{
9 A.H.U.S., Sección Ayuntamiento de Santiago, Libro 717, Varia, t. II, 1563-1698, doc. 42; Taín Guzmán, M., Los arquitectos..., op. cit., 161-162.

10 Sobre las obligaciones del canónigo obrero iriense véase Constituciones de la Insigne y Más Antigua Colegial de Santa María de Iria Flavia, mss. de 1661 del Archivo Histórico Diocesano de Santiago (A.H.D.S.), leg. 318 bis, fol. $5 r$. Véase también A.H.D.S., Fondo General, Colegiata de Iria, leg. 318, doc. 16, Memorial presentado por la villa al Yll ${ }^{m o}$. $s^{r}$. Monrroy suplicando mandase señalar sueldo al Mayordomo Fabriquero que lo hizo de 40 ducados como consta de su Decreto de 23 de noviembre de 1687, fol. 114 y ss.

11 A.M.P., Actas Consistoriales de Padrón, Caja 5, 1689, fol. 25r.v.

12 Para una visión general de la vida y obras de este artista véanse Pérez Costanti, P., op. cit., 90-91; Couselo Bouzas, J., op. cit., 248-249; Filgueira Valverde, J., «Sobre la biografía de Fray Gabriel de Casas», Cuadernos de Estudios Gallegos, 1946, 144-146; Bonet Correa, A., La arquitectura..., op. cit., 471-500; Fernández Gasalla, L., op. cit.; García Iglesias, X.M., El Barroco..., op. cit., t. XIII, 429-451; Fernández Álvarez, M." A., op. cit.

${ }^{13}$ A.H.U.S., Sección Ayuntamiento de Santiago, Libro 717, Varia, t. II, 1563-1698, doc. 42; Taín Guzmán, M., Los arquitectos..., op. cit., 162-166.
} 
El monje acompaña su informe con dos trazas, una planta (fig. 1) y una sección transversal de la colegiata (fig. 3), de buena calidad técnica y con escala. El pliego de papel en el que figuran contiene tres firmas: la del autor, la de Antonio Mariño y la de Francisco Grande. La primera traza representa la planta del antiguo templo medieval y de la capilla de San Ildefonso, respetados por Gabriel de Casas, así como alguna de sus reformas: los dos contrafuertes del ábside principal y el nuevo abovedamiento de todo el edificio. Varias notas manuscritas ayudan a la comprensión del dibujo ${ }^{14}$, en el que descubrimos el aprovechamiento que se hace de los contrafuertes medievales que, salvo en la cabecera, rodean en $U$ a la colegiata. Éstos no se distribuyen directamente pegados al muro, sino que hay un espacio intermedio libre con respecto a los paramentos. A tales contrafuertes en la documentación se les llama «arbotantes», lo que explica su planta, pues entre ellos y el muro media un arco de descarga de manera similar a como hoy se observa en la colegiata del Sar, con la diferencia de que en Iria han sido utilizados para construir una logia. Y es que, como se indica en la documentación, todo el perímetro aparece cubierto con un tejado y, además, según se observa en la planta, el lienzo norte se recorre con un parapeto de escasa altura, salvado por unos pocos escalones, dando lugar a un pórtico que recuerda al actual de la iglesia de San Salvador de Mao, si bien éste carece de arbotantes y, además, se cierra totalmente con un muro.

La sección del edificio es más parca en información. En ella figuran los pilares de las naves de la antigua basílica, la nueva cubierta pétrea propuesta por Gabriel de Casas, los tragaluces abocinados de las naves laterales, la logia generada por los estribos externos y el tejado montado «poniendole la armaçion de suerte que no cargue sobre la bobeda».

Pese a su calidad, parece que la oferta del arquitecto benedictino no convenció en un primer momento; quizás era un presupuesto excesivo para unas instituciones que siempre se han caracterizado por su escasez de medios. En consecuencia, «mandaron [que] della se aga publicacion asi en la ciudad de Santiago, villa de Ponteuedra y mas partes donde conuenga, para que auiendo otro mas vajo postor venga a poner su postura». Incluso se redactó un edicto o cédula que debió de distribuirse por las plazas de dichas localidades y en las puertas de sus iglesias, siendo leído por las calles a golpe de tambor por los pregoneros ${ }^{15}$. La reacción de Romay fue inmediata: el 19 de octubre, tras haber consultado «la postura hecha por el Padre Fray Gabriel de Casas y el rebajo que ase», declara que si la obra se hiciera siguiendo las plantas y condiciones del monje se compromete a realizarla por 85.000 reales, pero que si el

\footnotetext{
${ }^{14}$ Dicen lo siguiente: "Capilla de N.», «Presviterio y Capilla mayor», "Capilla de San Martín», "Las tres bobedas del crucero», "Capilla del Señor Ovispo», "Las tres bobedas de la nabe», "Las tres de las capillas», "Las tres de las capillas» y «Portico de la yglessia». En el reverso figura la nota siguiente: «Firmose esta planta por los señores de quien suena en el atrio de la iglesia colegial de Iria en veinte cinco dias del mes de febrero de mill y seiscientos y nobenta. Y lo firmo como scribano de numero y cabildo. Bartolome Lopez de Andrade».

${ }^{15}$ El texto del documento dice lo siguiente: «El lizenciado Don Antonio Mariño, canonigo y obrero de la Santa, Ynsigne y Mas Antigua Yglesia Collegial de Santa Maria de Yria Flauia, y el regidor Don Francisco Grande, que lo soy mas antiguo de la villa del Padron y su jurisdiçion, hasemos a sauer en como se trata de reedificar dicha Santa Yglesia de muchos reparos de que necesita y se expresan en la planta y condiçiones que paran en el ofiçio de Jacinto Gomez de Cançelada, scriuano de numero y ayuntamiento de dicha villa, para que los maestros de arquitectura que a ella quisieren aser postura acudan delante nosotros como diputados para ello nombrados a dicha villa del Padron dentro de diez dias, que corren desde el dia de la fecha desta, que se admitiran las lexitimas y remataran dicha obra en el mas vajo postor, dando las fianzas para ello necesarias, cuia redificazion hesta puesta en ochenta y ocho mill y sietecientos y quarenta reales; fecha en dicha villa del Padron a catorce dias del mes de septiembre de mill seiscientos y ochenta y nueue años. Antonio Mariño. Francisco Grande. Por su mandado, Jacinto Gomez. Es copia del edito original que se fixo en la puerta de la Santa y Apostolica Yglesia de Señor Santiago que sale a la Quintana della parte acostunbrada oy dia a mi presencia, y en fee dello como escriuano de su Magestad, vezino de la ciudad de Santiago, de pedimiento de la parte de la villa del Padron, lo signo y firmo en dicha ciudad a veinte y seis dias del mes de septiembre de mill seiscientos y ochenta y nueue años. En testimonio de verdad, Santiago Covelo». Sobre el tema véase Taín Guzmán, M., Los arquitectos..., op. cit., 54 y ss.
} 
N

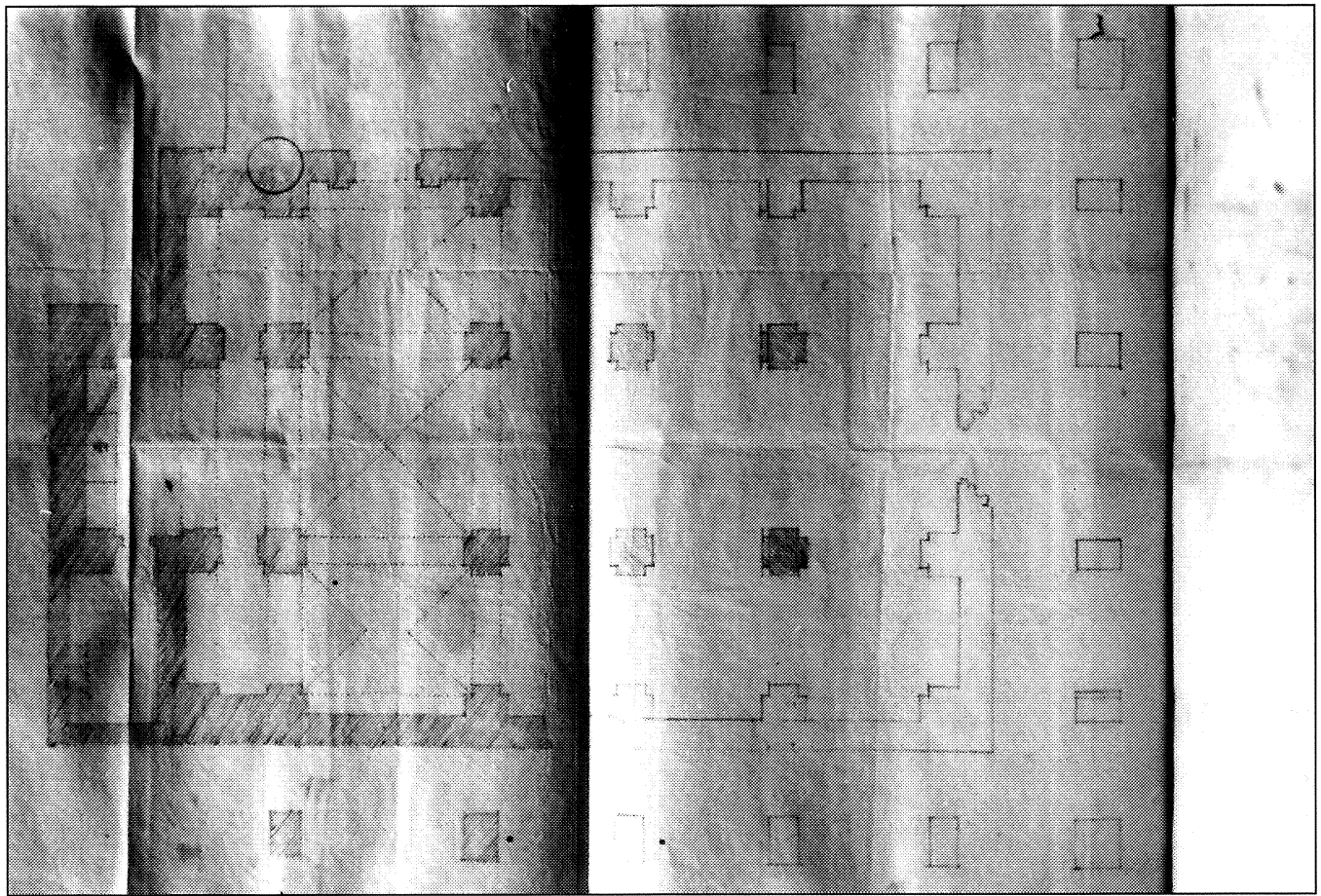

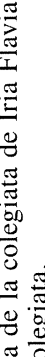

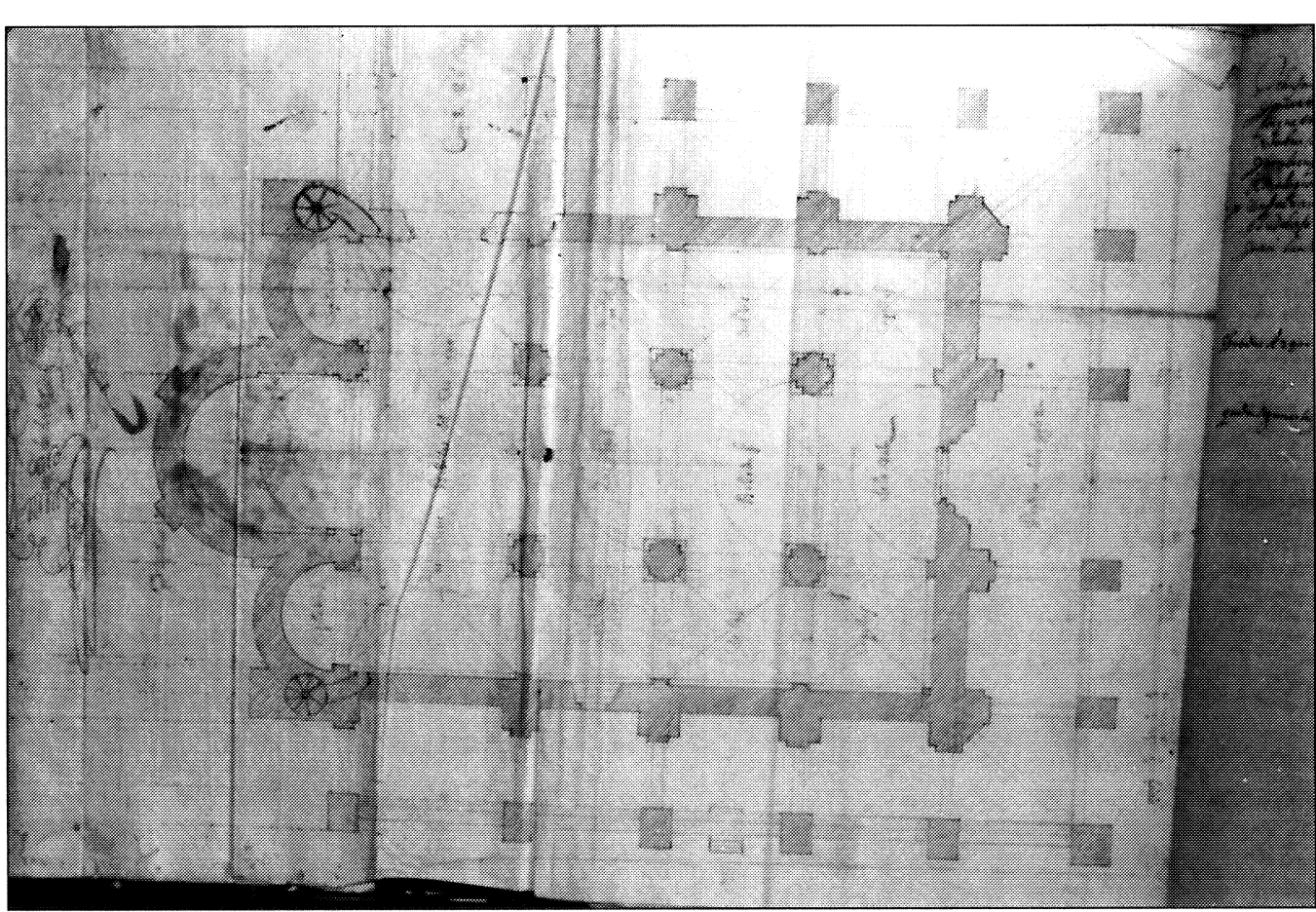

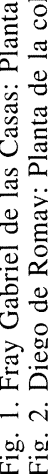


proyecto finalmente aceptado es el suyo, de mayor envergadura por la proyectada tribuna o pasillo alto, entonces valora la intervención en 93.738 reales ${ }^{16}$.

El 11 de enero de 1690 se reúnen los prebendados para decidirse por el plan de uno de los dos artífices y subastar definitivamente la obra. Y así «... visto y examinadas dichas plantas por este cabildo, determino que dicho señor canonigo obrero se ciña y siga la planta de dicho Padre Fray Gabriel de Casas, y sobre della siga, publique y reciua las posturas que en razon de la composicion de dicha yglesia se vbieren de hazer». El 23 de enero el consistorio padronés confirma la decisión capitular. Días después se informa a Gabriel de Casas de todo lo acordado y se anuncia en la Plaza de la Quintana la postura de Romay al proyecto del benedictino, por si algún maestro de obras de la ciudad quisiera presentar otra oferta ${ }^{17}$. Por fin, el 25 de febrero, en el atrio de la colegiata, Mariño y Grande deciden que «... en bista de que el ultimo postor a sido el Padre Fray Gabriel de Casas,... le haçen remate en forma de dicha obra en conformidad de la planta... firmada de dichos señores y de dicho Padre... y en conformidad de los declaraçiones de dicho Padre maestro presentadas ante dichos señores... en seis dias del mes de setienbre de dicho año pasado de ochenta y nuebe» en la cantidad de 84.960 reales ${ }^{18}$.

En el documento de la adjudicación definitiva se alude a la intención de acudir a la oficina de un escribano en Santiago para redactar y firmar el documento contractual. El motivo de su realización en la vecina ciudad y no en Padrón es por ser necesaria la firma del ya citado Francisco de Sanmamed, canónigo tesorero de la Catedral de Santiago y administrador del Hospital Real. Desconozco si tal escritura se llegó siquiera a redactar. En la reunión consistorial celebrada en Padrón el 28 de febrero, Francisco Grande informa a los ediles del remate de la obra y del ofrecimiento de Sanmamed de prestar 30.000 reales para comenzar la nueva empresa constructiva, pues «el dinero que tiene la Fabrica no llega» ${ }^{19}$. En la reunión del 8 de junio se leyeron dos cartas de Gabriel de Casas preguntando si puede comenzar «la execución de dichos reparos». La contestación de los ediles no deja lugar a dudas: «y visto por dichos señores acordaron que a tanto esta uilla tiene pleito sobre del dinero della [de la obra] con el fiscal eclesiastico se suspende por aora» ${ }^{20}$. En consecuencia, el monje arquitecto obtiene un auto del provisor de Santiago y el 6 de noviembre exige a los prebendados irienses el pago de «la planta y gastos que se le hauian causado», indemnización que acceden a abonar ${ }^{21}$.

\footnotetext{
16 A.H.U.S., Sección Ayuntamiento de Santiago, Libro 717, Varia, t. II, 1563-1698, doc. 42; Taín Guzmán, M., Los arquitectos..., op. cit., 166-168.

${ }_{17}$ El edicto dice lo siguiente: «El lizenciado Don Anttonio Mariño, canonigo obrero de la Santa Ynsigne y Mas Antigua Yglesia Colegial de Santa Maria del Yria Flauia, y el regidor Don Francisco Grande, que lo soi mas antiguo de la villa del Padron y su jurisdizion. Hacemos sauer en como se trata de redificar dicha yglesia de muchos reparos de que nezesita y se expresan en la planta y condiziones echas por el Padre Fray Gabriel de Casas que paran en el oficio del pressente scribano para que los maestros de arquitectura que a ella quisieren hazer postura acudan delante nosotros, como diputados para ello nombrados, a dicha villa del Padron dentro de veinte dias, que corren desde oy dia de la fecha desta, que se admitiran las lexitimas y remataran dicha obra en el mas vajo postor, dando las fianzas para ello nezesarias, y cuya redificazion esta puesta en ochenta y çinco mill reales de vellon, fecha en dicha villa a veinte y quatro dias del mes de henero de mill seiscientos y noventa años. Antonio Mariño. Don Francisco Grande. Por su mandado Jazinto Gomez. Doyme por sauedor de la uaja de la postura que menziona el edito de arriua y lo firmo en el Real de San Martín de Santiago a treinta de henero del año de mil seiscientos y noventa años. Fray Gabriel de Casas. Hes copia del edito original que refiere y oi dia de la fecha e uisto fijar en vna de las puertas de la Santa Yglesia de Señor Santiago desta ciudad que sale a la Quintana de los Muertos de ella, y en fe dello lo firmo en Santiago a primero dia del mes de febrero de mill seiscientos y noventa años. Antonio Lopez de Seoane».

18 A.M.P., Actas Consistoriales de Padrón, Caja 5, 1690, fols. 24v-25r.; A.H.U.S., Sección Ayuntamiento de Santiago, Libro 717, Varia, t. II, 1563-1689, doc. 42 (cfr. Taín Guzmán, M., Los arquitectos..., op. cit., 168-173).

19 A.M.P., Actas Consistoriales de Padrón, Caja 5, 1690, fol. 24v.

20 A.M.P., Actas Consistoriales de Padrón, Caja 5, 1690, fol. 32v. Meses después reclama al ayuntamiento le «diese satisfazion de su trauaxo y plantas» (A.M.P., Actas Consistoriales de Padrón, Caja 6, 1691, fol. 36r.v.). Entre el concejo de Padrón y el cabildo iriense se entabla un pleito a causa de cierta cantidad de dinero que se reclama al canónigo fabriquero, lo que va a impedir el comienzo de las obras (A.M.P., Testimonio de un pleito entre el cabildo de Iria y el concejo de Padrón, 1690).

21 A.H.D.S., Fondo General, Libro 25 de Actas Capitulares, 1691, leg. 327A, fols. 208v-209r.
} 
Años después las cosas seguían igual. En el acta consistorial del 9 de enero de 1693 se denuncia «... como la yglesia collegial de Santa Maria de Yria necesitaua de muchos reparos en su capilla mayor... y traydo maestros y echo sus plantas, asta aora no se avia efetuado...» ${ }^{22}$. Al día siguiente, Diego de Romay redacta unas condiciones de obra para la reconstrucción prácticamente completa del edificio en tres años que presupuesta en 90.779 reales ${ }^{23}$. En ellas expone la necesidad de construir una nueva capilla mayor, incluyendo, si hiciera falta, una nueva cimentación; las paredes «que forman el templo», con sillares bien cortados; los pilares de las naves y el crucero «con basas, capiteles y arcos... de semicírculo»; un espejo encima de la capilla mayor y un ventanal entre cada uno de los contrafuertes y encima del pórtico; la fachada principal «lisa» y con un «espejo para dar lus al coro»; así como bóvedas de arista en toda la colegiata salvo en la cabecera donde se harían de cañón. Mientras durase la obra se deberían desarmar los retablos de los tres ábsides «y los dos de los torales», y también cerrar con un muro la parte de la iglesia que se pueda ir utilizando - en concreto, las naves-, mientras se va trabajando en la cabecera y el transepto. En el documento se refiere varias veces a una planta y un alzado que se conservan: se trata de una planta del conjunto de la basílica (fig. 2) y de una sección longitudinal de la misma (fig. 4). En la primera, aparece representada tanto la parte de la colegiata antigua que el artista se propone respetar, incluida la capilla de San Ildefonso, como la que pretende reformar, esta última diferenciada de la anterior con un fuerte rayado. Así, se representa la nueva cabecera que desea construir, compuesta por una gran capilla mayor rectangular, sede del altar, y dos capillas laterales cuadrangulares mucho menos desarrolladas. Detrás de la del Evangelio se sitúa la sacristía —así lo indica una nota manuscrita- comunicada directamente con el presbiterio por una puerta abierta en el macizo de la pared medianera. También figuran los nuevos soportes de las naves y parte del abovedamiento. Un círculo dibujado con un compás en el muro de la Epístola indica la ubicación de la escalera que da acceso a las torre sur. En la traza también aparece la planta de sus contrafuertes medievales rodeando lo que queda del viejo edificio, como ya se ha visto en los dibujos de Fray Gabriel de Casas.

En la sección figura la firma del artista y varias leyendas explicativas ${ }^{24}$, y se representa el lado sur del edificio con un boceto de la portada de la capilla del Obispo de Quito. Este dibujo permite comprender el alcance de la reestructuración propuesta: los monumentales pilastrones del crucero, las dobles pilastras de la nave central, los arcos formeros, el cuarto de esfera que cubre la capilla mayor y su altar (señalado con una cruz), la habilitación de sendas capillas en el muro de los dos primeros tramos de la nave de la Epístola (supongo que en sendas hornacinas), los abovedamientos y arcos fajones de la nave principal, el nuevo sistema de iluminación a base de ventanales rectangulares abiertos en las paredes altas y de uno abocinado horadado en la fachada de acceso, así como el coro y la pequeña tribuna o pasillo alto de la nave central, estructuras estas últimas que no aparecen en el proyecto del benedictino.

En 1696 se sigue insistiendo sin resultado en la necesidad de empezar los trabajos... ${ }^{25}$. A finales de febrero se solicita dinero a los canónigos de la Catedral de Santiago — que dan 1.000 ducados en tres plazos - y al arzobispo Fray Antonio de Monroy que contesta que «... no podia tener numero a la oferta de lo que avia de dar, por no saver los caudales que avia en poder de su thessorero, pero que se empezase la obra que asistiria con quanto pudiese». Tal

\footnotetext{
22 A.M.P., Actas Consistoriales de Padrón, Caja 6, 6 de enero y 9 de enero de 1693, sin foliar.

${ }_{23}$ A.H.U.S., Sección Ayuntamiento de Santiago, Libro 717, Varia, t. II, 1567-1698, doc. 42, fol. 103r.v. En este escrito también hace otras propuestas opcionales más económicas de reconstrucción parcial de la colegiata.

${ }^{24}$ Son las siguientes: "Capilla mayor», «Señor Obispo», «Bobedas grandes del cuerpo de la yglesia», "Ventana de la claraboya», «Capilla», «Capilla» y «Puerta».

25 A.M.P., Actas Consistoriales de Padrón, caja 6, 1695.
} 


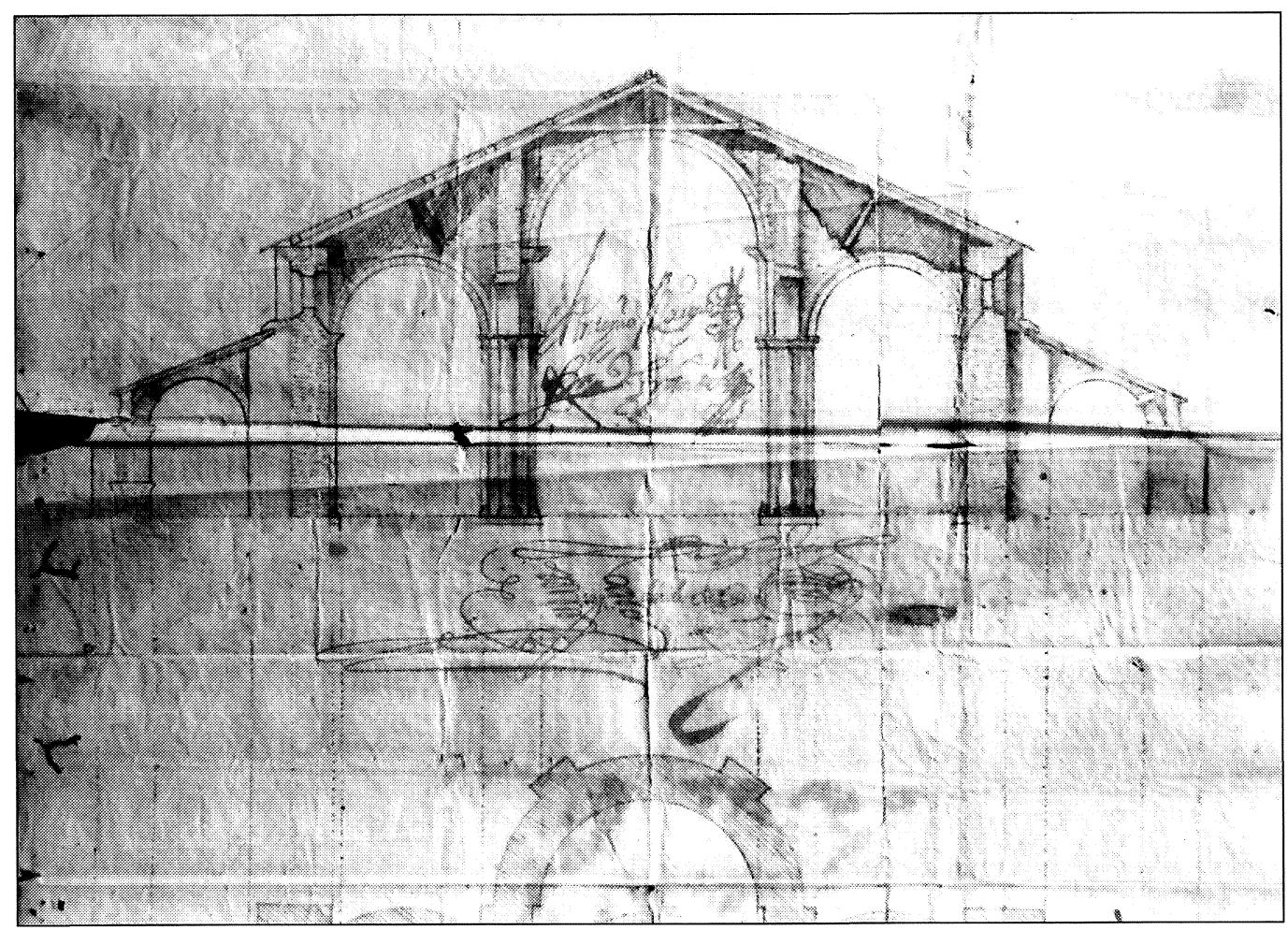

4

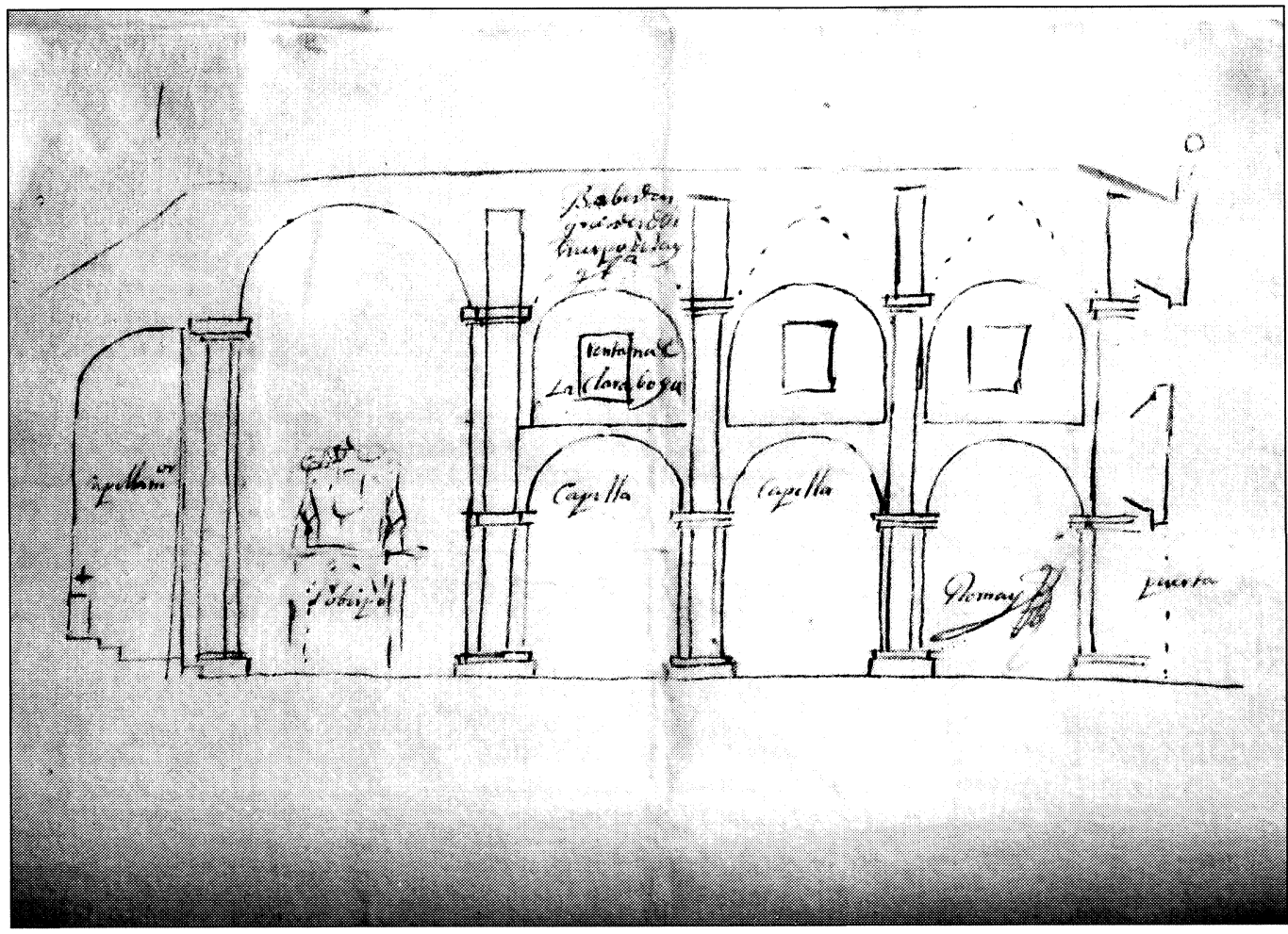

Fig. 3. Fray Gabriel de las Casas: Sección de la colegiata.

Fig. 4. Diego de Romay: Sección de la colegiata. 
operación se repite el 15 de marzo con el consistorio padronés que oferta 7.000 reales más «100 ducados que ymportaua el gasto de cera que se compartia entre aquel ayuntamiento en los dias de la Purificazion y San Juan Anteportam Latinam por 4 años» ${ }^{26}$. En dicha fecha también se requirieron los servicios de Domingo de Andrade, Maestro Mayor de Obras de la Catedral del Apóstol ${ }^{27}$, para que reconociese los desperfectos, de los que redacta un informe de conclusiones similares a los anteriores de Diego de Romay y de Gabriel de Casas, y dibuja varias trazas hoy perdidas ${ }^{28}$.

$\mathrm{Al}$ año siguiente las obras aún no habían empezado al haberse enzarzado el cabildo iriense y los ediles padroneses en un complidado pleito sobre sus respectivas prerrogativas y derechos en el templo. El consistorio denuncia que el cabildo trata «... de redificar y ampliar la capilla mayor de su Yglesia donde son parrochianos la Justicia y Regimiento y vecinos del Padron sin que dicha redificacion y ampliacion sea necessaria ni tener la collegiata los medios necessarios para ella, por considerarse hauer menester mas de 20.000 ducados, en que pretenden, segun la expresion de su animo, consumir los reditos de los censos que tiene la fundacion del reverendo obispo que fue de Quito, en que la Justicia y Regimiento son ynteresados. Y lo mismo en la contribuçion que pretenden los canonigos hagan los vezinos como parrochianos en que sean grabados mui considerablemente»; e incluso llega a decir que «... no se podia hacer fabrica alguna en la yglesia sin su consentimiento por ser su parrochia y tener en ella sus entierros, fundaciones y capillas. Y que para redificarse, como lo pretextaua el cabildo, hera preçiso que constase del reconoçimiento que deçia hauer hecho el maestro Andrade y otros peritos para que en su conformidad se sepa por que parte necesita de redificarse la yglesia y lo que importa. Y que aunque el cabildo alegaua no haçer repartimiento para la obra, podia

26 A.H.D.S., Fondo General, Colegiata de Iria, leg. 319, fol. 494r., y Libro 25 de Actas Capitulares, 1696, leg. 327A, fols. 222r-224v.; Archivo de la Catedral de Santiago (A.C.S.), Libro 44 de Actas Capitulares, leg. 487, 1696, fols. 32v.-33r. y $33 \mathrm{v} .-34$ r. El 27 de julio de 1696 se da un poder notarial al nuevo canónigo fabriquero Antonio de Vila y Miranda «... para que pueda cobrar, reçiuir y recaudar ttodas y qualesquiera canttidades de maravedies y ottros generos que dieren de limosnas para dicha fabrica y redificazion ansi su Yllustrisima dicho señor arçohispo como el yllustrisimo señor dean y cauildo [de Santiago] como de otras qualesquiera comunidades y particulares». El 4 de diciembre de 1697 recibe los primeros 1.833 reales del cuerpo capitular compostelano, repitiéndose la operación el 24 de julio de 1698 y el 11 de septiembre de 1699 (A.C.S., Fábrica. Comprobantes de cuentas, legs. 962-B y 963-A, escrituras y recibos). Se conservan dos cartas fechadas el 12 de julio de 1696 y el 22 de febrero de 1698 dirigidas por Monroy al cabildo de Iria a propósito de las obras (A.H.D.S., Fondo General, Colegiata de Iria, leg. 324, fols. 16r. y 17r.). Véase una de las contestaciones de los prebendados irienses pidiéndole más dinero del 13 de octubre de 1698 (A.H.D.S., Fondo General, Colegiata de Iria, leg. 324, fol. 247r.).

27 Para una visión general de la vida y obras de este artista véanse Murguía, M., El arte en Santiago..., op. cit., 199-200; López Ferreiro, A., Historia de la Santa A.M. Iglesia de Santiago de Compostela, t. IX y X, Santiago, 1983 (facsímiles de las ed. de 1907 y 1908); Pérez Costanti, P., op. cit., 15-23; González García-Paz, S., «Sobre Domingo Antonio de Andrade», Archivo Español de Arte y Arqueología, 1935, 279-282; Bonet Correa, A., La arquitectura., op. cit., 359-428; Mayán Fernández, F., Domingo Antonio de Andrade. Hijo ilustre de Cee, A Coruña, 1990; García Iglesias, X.M., A Catedral e o Barroco, Santiago, 1990; Idem, El Barroco..., op. cit., t. XIII, 336-377; Fernández Gasalla, L., op. cit.; Fernández Álvarez, M. a., op. cit.; Taín Guzmán, M., Domingo de Andrade, Maestro de Obras de la Catedral de Santiago (1639-1712), Santiago, 1998, 2 vols.

${ }^{28}$ A.H.D.S., Fondo General, Colegiata de Iria, Libro 25 de Actas Capitulares, 1696, leg. 327A, fols. 222v.-224v.; A.M.P., Actas Consistoriales de Padrón, Caja 6, 1696, sin foliar. Un documento nos informa del contenido del dictamen: «... que el maestro Andrade, auiendo bisitado toda la Yglesia de Santa Maria y echado el plomo a todas sus paredes y columnas, auia asegurado lo que antes de aora auian depuesto el Padre Fray Gabriel de Casas... y Diego de Romay..., y hes que toda dicha yglesia se benia al suelo por falta de çimientos bastantes en las paredes y reenpuxos en los estribos como se reconoçia en estar auierta la bobeda de la capilla mayor y los arcos de la nabe principal de dicha yglesia. Y que ansi se neçesitaba de fabricarse toda ella de nuebo desde los çimientos, menos la pared de la portada principal, la qual solo se auia de rebaxar asta debaxo del espexo y para fabricarse de nuebo desde allí arriba» (A.H.D.S., Fondo General, Colegiata de Iria, Libro 25 de Actas Capitulares, 1696, leg. 327A, fols. 223v.-224v.; el texto ha sido publicado por Taín Guzmán, M., Domingo de Andrade..., op. cit., vol. I, 92). Otro señala «que segun la planta y dictamen que hauia hecho el maestro Andrade tendria de coste la reedificacion 8.500 ducados» (A.H.D.S., Fondo General, Colegiata de Iria, leg. 318, fol. 263v.; A.H.U.S., Sección Ayuntamiento de Santiago, Libro 717, Varia, t. II, 1563-1698, doc. 42, fol. 89v.). Pérez Costanti (op. cit., 90), y después de él otros autores, se equivoca cuando afirma que Andrade concursó en 1690 con Diego de Romay y Fray Gabriel de Casas por la adjudicación de las obras de la colegiata. 
llegar el tiempo en que se pretenda sobre los parrochianos, sin embargo de estar obligado a redificarla por perçiuir las rentas y diezmos, y que con pretexto de que estos no lleguen procuraran obligar al ayuntamiento y feligreses al residuo, por lo qual hes preçiso el reconocimiento y sauer lo de que necesita para conseruarse en su primitibo estado. Y que el cabildo pretende ampliar la yglesia y darla nueba disposiçion para que son precisos muchos ducados y no hauia raçon...» ${ }^{29}$. En 1698 los prebendados y los ediles firman una concordia «sobre el modo de reunir fondos para la reedificacion de la iglesia colegial» ${ }^{30}$. Según una carta del mes de julio la colegiata ya estaba «... abierta por todas partes y prinçipiadas las bobedas de las sacristias sobre las quales se a de formar la de su capilla mayor, faltando el dinero con que pagar a los ofiçiales» ${ }^{31}$. Tales trabajos, es de suponer, se realizan siguiendo el proyecto de

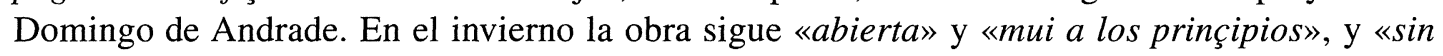
proseguirse en ella», dada la endémica falta de recursos económicos que impedirá todavía durante algún tiempo la reconstrucción ${ }^{32}$.

Un documento de mayo de 1705 indica que «la yglesia de Santa Maria se allaua por cubrir de maderas, teja y lo demas nezesario [y] que con la continuazion de los temporales la obra principiada algunos años auia estaua mui deteriorada». El cabildo decide entonces «... se socorriese dicha obra con 10.000 reales que consignaron en la mayordomia desde el año de 1699 asta fin del dicho de 705, y que el capitular que en ella no tubiese lo que le correspondiese se obligase a pagar lo que faltase dentro de año y medio» ${ }^{33}$.

El 8 de mayo de 1708 se concierta con el maestro de obras pontevedrés Pedro García en 39.000 reales la construcción en treinta meses de las bóvedas del crucero «según la planta que auia entregado a dicho cauildo» ${ }^{34}$. En julio, los canónigos se reúnen una vez más para estudiar la manera de obtener nuevos fondos, pues «la dicha yglesia de Santa Maria se hallaba casi hyerma, sin probabilidad de conseguirse medios para su reedificacion y finaliçar su $o b r a »{ }^{35}$. Providencialmente, en septiembre el arzobispo ofrece 6.000 reales «... para ayuda de la obra de la Yglesia de Nuestra Señora» con la obligación de celebrar algunas misas ${ }^{36}$. Pero en noviembre de 1711 otra vez la construcción «por falta de medios estaba parada», pidién-

\footnotetext{
${ }^{29}$ Existe un resumen pormenorizado de los enfrentamientos entre ambas instituciones en A.H.D.S., Fondo General, Colegiata de Iria, leg. 318, fols. 252r.-253v. y 259r.-274v. Sobre el tema consúltese A.M.P., Actas Consistoriales de Padrón, caja 6, 1697, fols. 13r.v., 33r., 34r., 35r.v., 37r., 41r.-50r., 51r.v., 58r. y ss., y 65r.v.; A.H.D.S., Fondo general, Colegiata de Iria, leg. 318, doc. 17, fols. 116r.-119v.; A.H.U.S., Sección Ayuntamiento de Santiago, Libro 717, Varia, t. II, 1563-1698, doc. 42.

${ }^{30}$ A.M.P., Mazo $3 .^{\circ}$, Concordia entre el concejo de Padrón y el cabildo de Yria sobre el modo de reunir fondos para la reedificacion de la iglesia colegial y otras cosas, 1698.

31 A.H.D.S., Fondo General, Colegiata de Iria, leg. 324, carta de los prebendados de Iria a Monroy, fol. 250r.

32 El cabildo iriense decidió entonces se aplicase para la obra «el producto de la Mesa Capitular durante dicha obra», aunque no todos los prebendados estuvieron de acuerdo (A.H.D.S., Fondo General, Colegiata de Iria, leg. 319, fol. 494r., y Libro 25 de Actas Capitulares, 1698, leg. 327A, fols. 229r.-230r.).

33 A.H.D.S., Fondo General, Colegiata de Iria, leg. 319, fol. 494r., y Libro 25 de Actas Capitulares, leg. 327A, fols. 255r.-256r.

${ }^{34}$ «Que se componen de quatro cepas y seis bobedas con las paredes correspondientes». A.H.D.S., Fondo General, Colegiata de Iria, Libro 25 de Actas Capitulares, leg. 327A, 1708, fols. 269v.-270r.; A.H.U.S., Sección Protocolos de Padrón, leg. 3.401, Fco. Buceta Señoráns, 1708, fol. 40r.v.; cfr. Couselo Bouzas, J., op. cit., 373. Para una visión general de la biografía y las obras de este artista véanse Couselo Bouzas, J., op. cit., 372-375; Bonet Correa, A., La arquitectura..., op. cit., 501-508; Taín Guzmán, «El Maestro de Obras Pedro García y la villa de Pontevedra», Compostellanum, 1996, 451-476.

35 A.H.D.S., Fondo General, Colegiata de Iria, Libro 25 de Actas Capitulares, leg. 327A, 1708, fols. 271 v.-273r.

36 A.H.D.S., Fondo General, Colegiata de Iria, leg. 324, cartas de Francisco Verdugo al cabildo de Iria, fols. 111 r. y 112r.v. Sobre este prelado véanse Barreiro, B., Monroy. Leyenda histórica, Pontevedra, 1884; Altamira, R., «El arzobispo Monroy y Felipe V (nuevo documento para la historia del regalismo en el siglo XVIII), Revista crítica de historia y literatura, t. V, 1900, 27-30 y 60-70; Pazos, M. R., Episcopado gallego. Arzobispos de Santiago, Madrid, 1946, 227-237; Hernández, R., «El cartulario del obispo dominico compostelano Antonio de Monroy (1715)», Compostellanum, 1977, 261-298; Ríos Miramontes, M. ${ }^{\mathrm{T} T}$., «El arzobispo Monroy: notas para su biografía», Archivo Ibero-Americano, 1984, 327-350; Idem, Aportaciones al Barroco Gallego. Un gran mecenazgo, Santiago, 1986 (el capítulo de este libro dedicado a la colegiata fue publicado independientemente por su autora bajo el título «La Colegiata de Santa María de Iria, de Padrón», Archivo Íbero-Americano, 1983, 365-380).
} 
dose la ayuda del prelado quien envió en enero a sus comensales Francisco Verdugo, mayordomo, Pedro Atanasio, secretario de cámara, junto con Felipe de Santamaría, abogado, y Fernando de Casas, maestro de obras de la Catedral, para que elaborasen un presupuesto de lo que faltaba por construir. Y así «... havian pasado a reconozer la obra con el maestro Pedro Garcia, que avia hecho lo que estava ejecutada en la Yglesia de Santa Maria. Y, conferenciado sobre ella, se retiraron a dar quenta a Su Yllustrisima quien insinuo al cavildo por carta que escrivio dicho mayordomo al señor vicario daria 5 mil ducados para fenezer la obra. En vista de que determino este cavildo pasasen 2 legados a dar las grazias a Su Yllustrisima con poder para percivir dichos 5 mil ducados» ${ }^{37}$. Por fin, y gracias a ese dinero, el 26 de enero de 1712 se ajusta con el mismo Pedro García la terminación y pavimentado del edificio. Así se compromete a la construcción del resto del abovedamiento y a la reestructuración de la fachada occidental siguiendo la «plantta que dicho maestro abia ydeado». En cuanto al antiguo pórtico exterior, se ajusta únicamente la construcción de «... dos arcos a los lados del nordes y bendabal, a cada vno el suio, anssi para el refujio de la gente como para que yndusga[n] su primitibo estado y antiguedad de dicha yglesia, [y] sin deshacer su portada principal» ${ }^{38}$.

En enero de 1714 el mismo artífice concierta la construcción de la derruida torre norte y el «alpendre de dicha yglesia», estructura esta última que podría corresponder a una parte del pórtico externo ${ }^{39}$. La nueva colegiata estaba definitivamente terminada en el verano del citado año, siendo bendecida el 8 de agosto por el canónigo Francisco Secadis en presencia de todo el cuerpo capitular y de «la santa ymagen de Santa Maria de Yria en su capilla mayor en la caja de su antiguo retablo» ${ }^{40}$. Inmediatamente, el propio arzobispo subvencionó la construcción de la reja del presbiterio, obra del cerrajero Clemente Lorenzo ${ }^{41}$, y de un nuevo retablo mayor, que hizo el entallador Miguel de Romay siguiendo sus propios dibujos ${ }^{42}$.

Si comparamos el trabajo de Pedro García con las trazas de Diego de Romay y Fray Gabriel de Casas se observan puntos en común ${ }^{43}$ (figs. 5-8). Y es que el artista pontevedrés respetó la planta medieval de la colegiata, salvo la cabecera, que si bien es también tripartita, se resuelve de forma rectangular como en el dibujo de Romay y es más profunda, cubierta con bóvedas de cañón y con dos sacristías detrás de las capillas laterales ${ }^{44}$. Los soportes y los

\footnotetext{
${ }^{37}$ Enseguida, tal suma se aumentó a 60.000 reales para la construcción de la reja del presbiterio. Según esa visita sólo quedaba por construir algunas «pilastras y bobedas [y la] torre a la parte del norte que esta cayda; y poner vidrieras a las ventanas que estan echas y las que se han de haçer en dicha yglesia; y losar toda ella con sus capillas y sacristias». A.H.D.S., Fondo General, Colegiata de Iria, leg. 319, fol. 494v., y Libro 25 de Actas Capitulares, leg. 327A, 1711-1712, fols. 284v.-285v. y 286r.-287r.

${ }^{38}$ Todo por 41.500 reales (A.H.U.S., Sección Protocolos de Padrón, leg. 3.405, Fco. Buceta Señoráns, 1712, fol. 5r.v.; cfr. Couselo Bouzas, J., op. cit., 373-375). Por este concierto y el de 1708 se emite carta de finiquito el 21 de septiembre de 1713 (A.H.U.S., Sección Protocolos de Padrón, leg. 3.405, Fco. Buceta Señoráns, 1713, fol. 49r.v.).

39 Todo ello por 6.700 reales (A.H.D.S., Fondo General, Colegiata de Iria, Libro 25 de Actas Capitulares, leg. 327A, 1714, fol. 301r.). Para reparar dicho alpendre se compraron en 1785 varios lotes de clavos (A.H.D.S., Fondo General. Colegiata de Iria, leg. 331, Libro para asiento de libranzas y gastos de la Yglesia de Santa Maria de Yria Flabia, fol. 122v.).

40 A.H.D.S., Fondo General, Colegiata de Iria, Libro 25 de Actas Capitulares, leg. 327A, 1714, fol. 308r.v.

${ }_{41}$ Su construcción se venía gestando desde febrero de 1712 (A.H.D.S., Fondo General, Colegiata de Iria, leg. 319, fol. 494v. y Libro 25 de Actas Capitulares, leg. 327A, 1712, fols. 286v.-287v.). Cfr. Ríos Miramontes, M. ${ }^{a}$ T., Aportaciones..., op. cit., 408-410.

${ }^{42}$ En el auto capitular del 3 de agosto de 1714 «... consta que aviendose presentado al Yll ${ }^{\circ}$. Sr. Arzobispo Monrroy vna planta que para el retablo de Santa Maria avia hecho el maestro Miguel de Romay, se avia agradado de ella y avia escrito al cavildo la pusiese en obra por dicho maestro» (A.D.H.S., Fondo General, Colegiata de Iria, leg. 319, fol. 494v.). En febrero de 1716 el retablo ya está asentado, enviándose entonces a un dorador (A.H.D.S., Fondo General, Colegiata de Iria, leg. 324, carta de Francisco Verdugo al cabildo de Iria, fol. 113r.). Sobre el retablo véanse Murguía, M., El Arte en Santiago.., op. cit., 229-230; Couselo Bouzas, J., op. cit., 595; Otero Túñez, R., «Miguel de Romay, retablista», Compostellanum, 1958, 199-200; Ríos Miramontes, M. 'T., Aportaciones..., op. cit., 399-406.

${ }^{43}$ Parece evidente que debió consultarlas y posiblemente también las perdidas de Andrade, el cual sí las conocía.

${ }^{44}$ El edificio de la actual colegiata ha sido estudiado por Bonet Correa, A., La arquitectura..., op. cit., 505-507; Ríos Miramontes, M. ${ }^{a}$ T., Aportaciones..., op. cit., 391-399.
} 

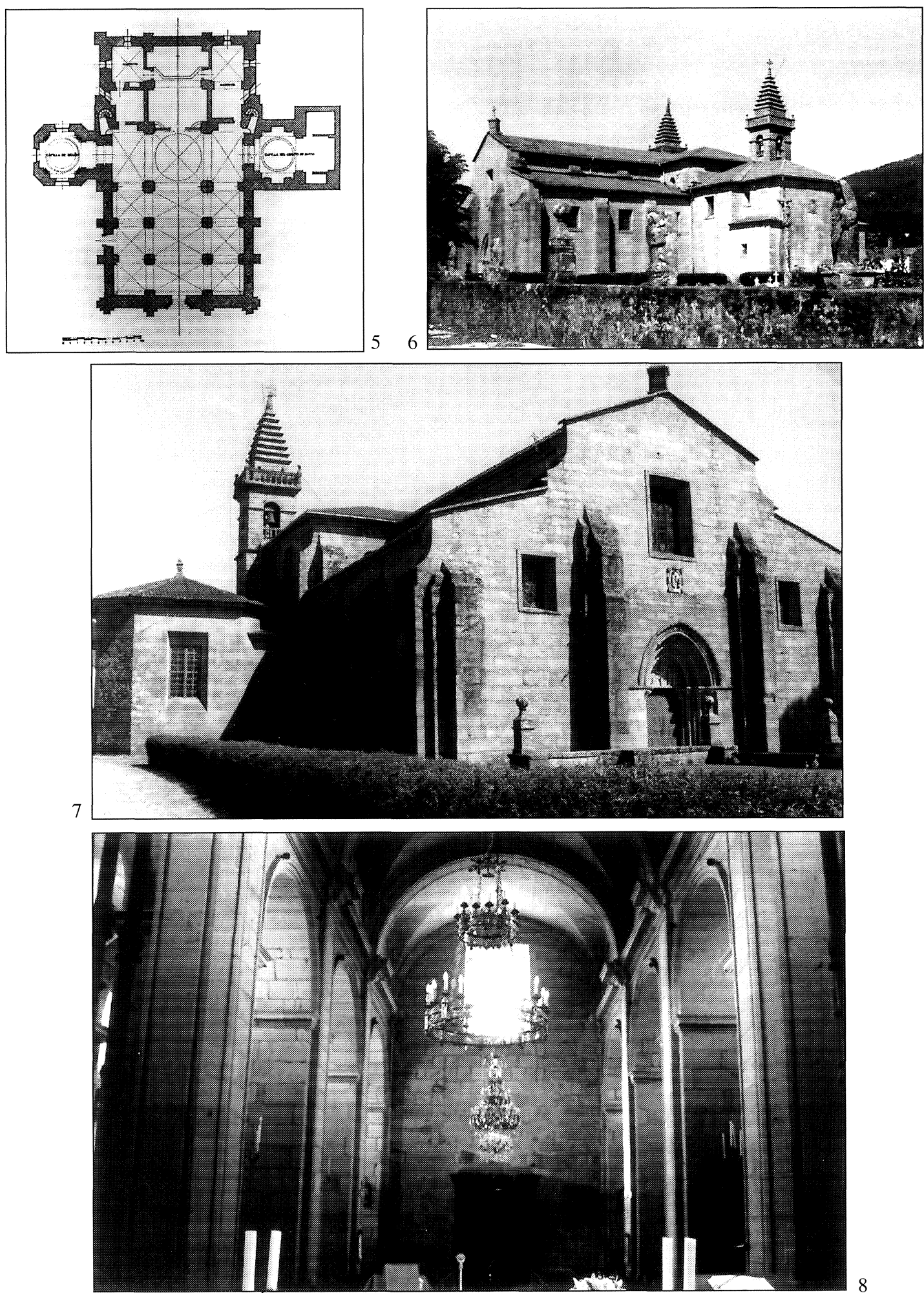

Fig. 5. Planta actual de la colegiata.

Fig. 6. La colegiata.

Fig. 7. Fachada occidental de la colegiata.

Fig. 8. Naves de la colegiata. 
abovedamientos también fueron renovados, contruyendo, en el crucero y en las tres naves, pilares y pilastras de orden toscano que sostienen bien bóvedas de cañón en la nave central y brazos laterales del crucero, bien de arista en las otras naves y en el tramo central del transepto (fig. 8). Los arbotantes se suprimieron, sustituyéndolos por estribos adosados directamente al muro. Desconozco si el pórtico exterior se respetó en su totalidad. De él hoy no quedan restos apreciables, salvo el pavimento pétreo y los cimientos del muro del porche norte: en 1785 aún se paga a un carpintero por reparar «el faiado de el portico de Santa Maria» ${ }^{45}$. En cambio, se mantiene la antigua portada de la fachada, con el tímpano decorado con una Epifanía, quedando las marcas del antiguo tejado del pórtico frontal. Las dos torres de remate escalonado ${ }^{46}$, accesibles por una escalera de caracol, ya aparecían en la planta de Gabriel de Casas. La sur ya existía, pues es mencionada en el informe del benedictino ${ }^{47}$. La norte fue reconstruida, imitando la anterior, por el artífice pontevedrés ${ }^{48}$. En la capilla de San Ildefonso no hubo ningún cambio, llegando a nuestros días prácticamente igual a como fue construida. Para iluminar el interior del templo se horadan tres ventanales en la fachada principal, uno para cada nave, otros en el crucero y en la cabecera, y un tragaluz en cada tramo de las paredes laterales, pero ninguno en los de la nave central donde los lunetos se ciegan: de ahí la oscuridad que padece en el edificio. La nave central y las laterales presentan tejados diferentes, el primero más alto que los otros, dando a la colegiata el aspecto de una antigua basílica.

La sobriedad del resultado obtenido en Iria y el respeto por la fábrica primitiva remiten a la única y muy modesta arquitectura eclesial que se conoce de Pedro García, la iglesia del vecino convento franciscano de San Antonio de Herbón, en cuya construcción estaba trabajando cuando fueron reclamados sus servicios por los prebendados irienses ${ }^{49}$.

\section{LA TRAZA DE LA SILLERÍA DE CORO DE MIGUEL DE ROMAY}

En el cabildo del 30 de julio de 1712 se decide construir una sillería de coro para el presbiterio de la nueva colegiata de Iria con la madera «que auia en el atrio de dicha yglesia que se allaba cortada» ${ }^{50}$. En los días siguientes, ajustan el mueble con el entallador Miguel de Romay ${ }^{51}$ y así en dos reuniones capitulares del 12 y 23 de julio «... se determinó que para hazer la silleria de coro de Santa María, que estava ajustada con el maestro Miguel de Romay en 300 ducados, inclusas dos tribunas, la vna para el organo y la otra en correspondencia del otro lado para uniformidad, se pagase en la manera siguiente: que las tribunas fuesen de quenta de la Fabrica; las sillas de las cappellanes de los alcanzes que devian algunos señores canonigos minerveros que avian sido de la fundacion de la Octava del Corpus y se estavan deviendo al cavildo; y las de los señores capitulares, lo que faltase para ellas, se repartiese entre dichos señores». Los prebendados también resolvieron que «dicho maestro prinçipiase con dicha obra con lo que contenia dicha planta en tanto que el cauildo resolveria y discurriria

\footnotetext{
45 A.H.D.S., Fondo General, Colegiata de Iria, leg. 331, Libro para asiento..., op. cit., fol. $93 \mathrm{v}$.

${ }^{46}$ El remate de dichas torres es similar al de la Torre de la Vela y al de la Torre del Tesoro de la Catedral de Santiago. Cfr. Bonet Correa, A., La arquitectura..., op. cit., 507.

47 A.H.U.S., Sección Ayuntamiento de Santiago, Libro 717, Varia, t. II, 1563-1698, doc. 42; cfr. Taín Guzmán, M., Los arquitectos..., op. cit., 163.

${ }^{48}$ Cfr. Bonet Correa, A., La arquitectura.., op. cit., 505; Ríos Miramontes, M. ${ }^{a}$ T., Aportaciones..., op. cit., 395.

49 Al respecto véase Bonet Correa, A., La arquitectura..., op. cit., 502-504.

50 A.H.D.S., Fondo General, Libro 25 de Actas Capitulares, leg. 327A, 1712, fol. 291r

51 Para una visión general sobre la biografía y obras del entallador véanse Couselo Bouzas, J., op. cit., 591-598; Otero Túñez, R., Miguel de Romay..., art. cit., 193-208; García Iglesias, X.M., El Barroco (II). Arquitectos del siglo xvill. Otras actividades artísticas, Galicia. Arte, t. XIV, A Coruña, 1993, 286-302.
} 
[de] donde saliesen los medios para dicha obra del choro» ${ }^{52}$. Enseguida, en su taller compostelano Romay comienza su realización no exenta de contratiempos. El 30 de mayo de 1713 los canónigos deliberan que «para mayor decençia de dicha silleria era preçisso hazer... unas targetas en las espaldas de las sillas», encargándose al fabriquero Fadrique Martínez su concierto con el artista «en lo menos que pudiese» ${ }^{53}$. El 20 de diciembre ya había terminado e instalado en Iria la sillería y las tribunas, solicitando se le abonasen los 885 reales que se le debían ${ }^{54}$. Un día después cobra el trabajo ${ }^{55}$.

La traza citada en la documentación se conserva y presenta abundantes notas manuscritas ${ }^{56}$ (figs. 9 y 10). En ella se representa un mueble de un único orden de sillas compuesto de cinco asientos. Cada uno presenta los brazos adornados con dobles volutas y hojarasca, el espaldar decorado con un motivo cuadrangular, así como la tabla del asiento abatible y con una misericordia vegetal. El central es el sitial presidencial y aparece diferenciado del resto en el adorno de los brazales con sendos grifos y del respaldo con un motivo circular.

Sobre las sillas corales se desarrolla un amplio friso dividido en cinco calles por pilastras toscanas de festón rehundido, cuyo capitel y fuste se ocultan bajo una cartela de hojas y una delgada sarta de frutas. Sólo la calle central presenta columnas corintias, una con la columna segmentada y la otra lisa, dando opción al cliente a decidirse por una de las dos. Los seis soportes se apoyan a su vez en diferentes tipos de ménsulas, las de los extremos sedes de una cartela vegetal de talla cactiforme, las siguientes de una tarjeta rehundida y las dos centrales de sendos mascarones. Los tableros aparecen decorados con arcos, de medio punto los impares y adintelados los pares. Unos y otros es muy posible que se destinasen a enmarcar algún relieve, aunque en el dibujo aparecen en blanco y sin ninguna indicación. El guardapolvo avanza en planta a la altura de los soportes, sobre los que descarga una consola de traza curvilínea que se decora con una hoja de acanto. Encima de cada una de ellas figuran querubines en diversas actitudes, de acuerdo con la afición demostrada por Miguel de Romay años antes en la construcción de las cajas de los dos órganos de la Catedral de Santiago ${ }^{57}$.

La calle central aparece también dignificada en esta parte del mueble. En el friso, el banco se adorna con motivos acantiformes y el arco del tablero central presenta una grapa fitomorfa, de talla cactiforme en el clave y follaje en las albanegas. Como remate, sobre el alero se levanta una peineta compuesta por un frontón curvilíneo partido, con los arranques del semicírculo terminados en volutas, y por un edículo rectangular. El panel central de este último presenta forma de U, rodeado por espirales y un tupido follaje, y coronado por un broche acantiforme de talla rizada.

Tal dibujo del mueble fue realizado con algunas modificaciones por duplicado, ocupando el primer tramo de la capilla mayor, lugar donde aún puede verse (fig. 17). Un cuerpo de asientos se dispone en el muro izquierdo, debajo del órgano, y el otro, haciéndole frente, en el muro derecho. Uno y otro son exactamente iguales. Entre ellos queda el amplio espacio del presbiterio, aislado de las naves por una reja, destinado a la celebración de los oficios.

\footnotetext{
52 A.H.D.S., Fondo General, Colegiata de Iria, Libro 25 de Actas Capitulares, leg. 327A, 1712, fols. 292v-293v., y leg. 319, fol. $494 \mathrm{v}$.

53 Tales tarjetas no se llegaron a ejecutar. A.H.D.S., Fondo General, Colegiata de Iria, Libro 25 de Actas Capitulares, leg. 327A, 1713, fol. 294v.

54 A.H.D.S., Fondo General, Colegiata de Iria, Libro 25 de Actas Capitulares, leg. 327A, 1713, fol. 300v. Una síntesis de la historia del mueble en Ríos Miramontes, M. ${ }^{a}$ T., Aportaciones..., op. cit., 406-407.

55 A.H.U.S., Sección Ayuntamiento de Santiago, Libro 719, Varia, t. IV, doc. 51.

56 A.H.U.S., Sección Ayuntamiento de Santiago, Libro 719, Varia, t. IV, doc. 51. De la existencia de la traza ya dio noticia Couselo Bouzas, J., op. cit., 596. Las notas manuscritas son las siguientes: "Ha de rematar en dos tribunas de cada lado [la] suia, y una es para el organo y la otra para hacer correspondencia a la obra por la perfecion», "Padron, jullio 10 de 1712. Planta de coro la hizo el maestro Miguel de Romay. Encima del dos tribunas correspondientes, la una para el organo. Doctor Somoza», "Concordose con el en dicho dia en 300 ducados estando presentes el señor Romero, señor Martinez, señor Don Fadrique, señor Paseiro e yo».

57 Cfr. Otero Túñez, R., Miguel de Romay..., art. cit., 194-197.
} 


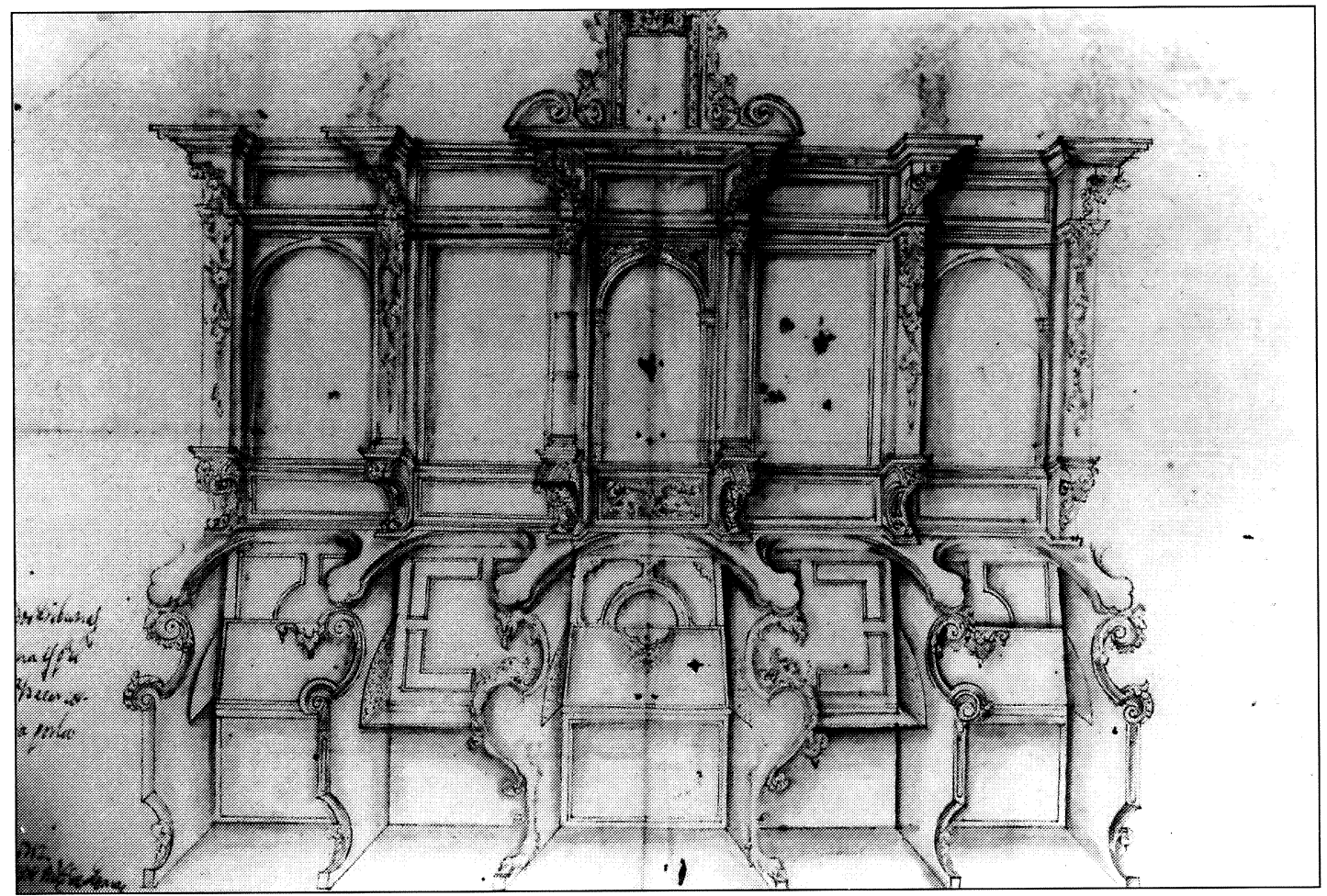

9

10

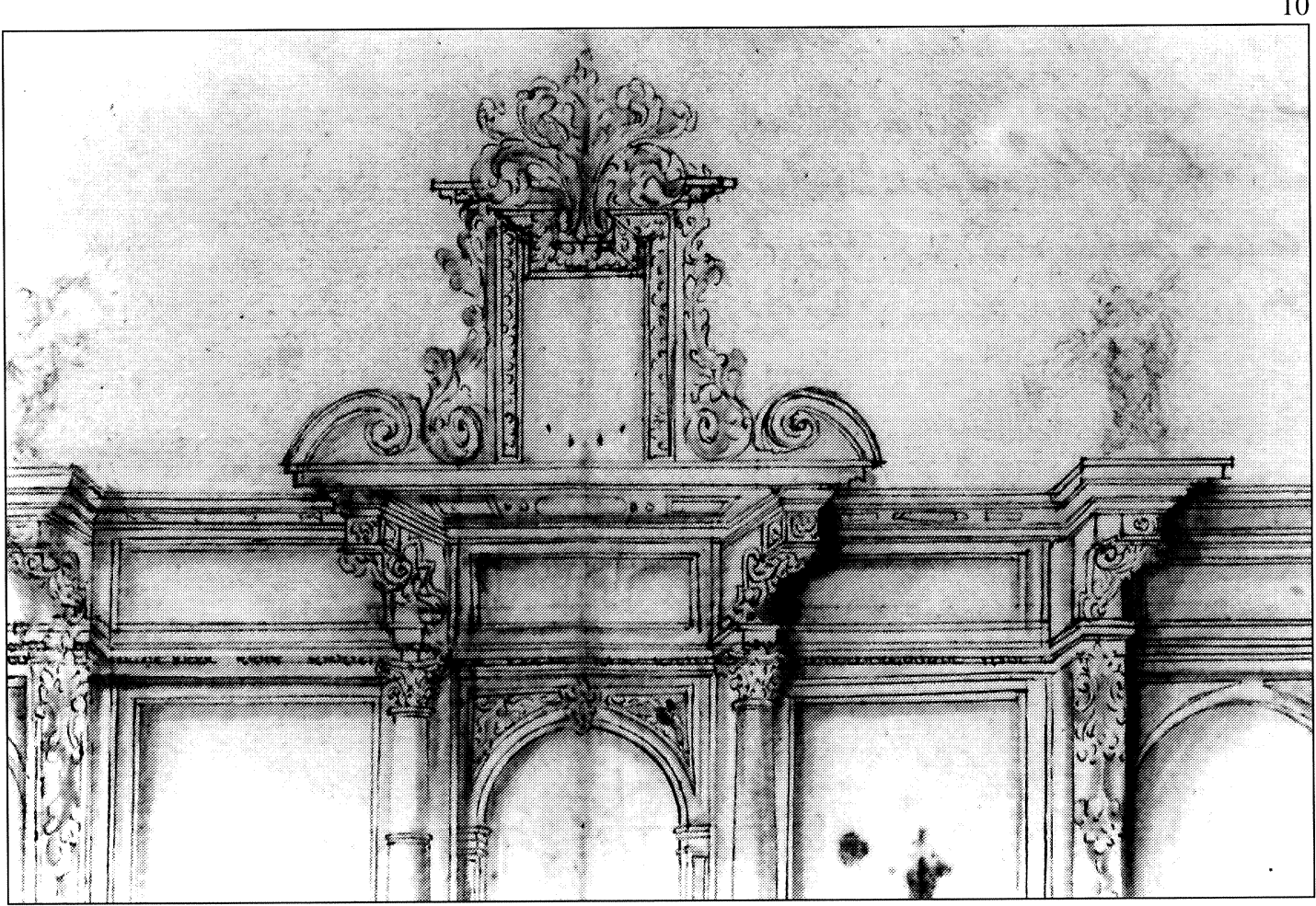

Figs. 9-10. Miguel de Romay: Traza de la sillería de coro de la colegiata. Conjunto y detalle. 
La principal variante de las dos partes de la sillería con respecto al proyecto es que cada una cuenta con un doble orden de asientos, el inferior de cuatro sillas y el superior de cinco, si bien ambos recuerdan a lo originalmente ideado por su autor. Las cuatro sillas bajas presentan el respaldo y el tablero del friso decorado con un motivo rectangular rehundido. Este último aparece delimitado en todos los casos por pilastrillas corintias de fuste estriado. Como guardapolvo aparece un atril corrido para las sillas altas, decorado con roleos y flores, y apoyado en acantos avolutados en eje con los soportes inferiores. El asiento central se suprime porque en su lugar se dispone la escalera de acceso a la sillería superior. Ésta repite el motivo decorativo del respaldo ya visto, pero presenta un friso mucho más desarrollado parecido al del dibujo. Cada tablero se decora con un doble arco de medio punto y se flanquea con pilastras con el fuste recorrido de trenzas de peras, membrillos y granadas sobre ménsulas vegetales. En eje con los soportes se distribuyen las consolas acantiformes de la tribuna superior, cuyo reverso se orna de diferentes tipos de flores completamente abiertas. La tribuna de la izquierda sirve de peana al órgano superior que contrató el organero compostelano José Crespo el 31 de agosto de $1726^{58}$, mientras que la de la derecha no contiene nada.

Los cambios que Miguel de Romay introduce en la sillería con respecto al plan original se inspiran claramente en la antigua sillería de la Catedral de Santiago de 1599, obra de Gregorio Español y Juan Dávila, que hoy se encuentra depositada en el monasterio de Sobrado ${ }^{59}$. Aunque el mueble iriense carece de los relieves figurativos del compostelano, repite sus dos cuerpos de sitiales con su ornato geométrico, las pilastras corintias de fuste acanalado de los paneles de la sillería baja, el atril corrido apoyado en ménsulas avolutadas, los arcos de los paneles rectangulares de las sillas altas, las consolas del cuerpo superior, etc. Es aportación del entallador la decoración barroca a base de ristras fruteras, hojarasca y broches vegetales. Tal vocabulario ornamental era corriente en los retablos desde la construcción, décadas antes, del aparato de la capilla mayor de la Catedral de Santiago ${ }^{60}$, siendo aplicado por primera vez a una sillería en la de la Catedral de Tui, por parte de Francisco de Castro Canseco en $1700{ }^{61}$, y especialmente en la del convento compostelano de Santa Clara, cuyas trazas se atribuyen a Domingo de Andrade y se fechan de los primeros años del siglo XVIII ${ }^{62}$.

\section{LAS NUEVE CASAS DE LOS CANÓNIGOS}

Según las Constituciones, los canónigos de la colegiata de Iria tenían la obligación de «residir» su prebenda al menos nueve meses al año ${ }^{63}$. Por ello la gran mayoría de ellos tenían fijada su residencia dentro del entramado urbano de la villa de Padrón. De ahí la necesidad de construir el nuevo edificio residencial próximo a su iglesia hoy conocido como Casas de los

\footnotetext{
58 A.H.U.S., Sección Ayuntamiento de Santiago, Libro 719, doc. 52.

59 Próximamente, con motivo de una exposición, se va a volver a trasladar el mueble a Santiago y se va a instalar en el coro alto de San Martín Pinario.

${ }^{60}$ Cfr. Taín Guzmán, M., Domingo de Andrade..., op. cit., vol. I, 353-400.

${ }^{61} \mathrm{Al}$ parecer, alrededor de las mismas fechas que la sillería iriense, Castro Canseco construyó la del monasterio de Celanova. Cfr. Caramés González, C., «El escultor y entallador Francisco de Castro Canseco (1693-1724)», Boletín Auriense, 1972 , t. II, 167-192.

${ }^{62}$ Cfr. Folgar de la Calle, M. ${ }^{a}$ del C., «La obra de Pedro de Arén en el convento compostelano de Santa Clara», En torno al arte auriense, Homenaje a D. José González Paz, Santiago, 1990, 135; Taín Guzmán, M., Domingo de Andrade..., op. cit., vol. I, 447-448. Sobre los vínculos entre Andrade y Miguel de Romay véase Taín Guzmán, M., Domingo de Andrade..., op. cit., vol. I, 66.

${ }^{63}$ Así lo especifica la constitución 11 titulada «De la residençia de los Canonigos». Ésta, entre otras cosas, dice: «El canonigo que residiere nueue meses en un anno podra tomar los tres que faltaren para cumplimiento del dicho anno para su recreaçion y para sus negocios sin pedir liçençia, y sera contado en ellos por residente y ganara enteramente su prebenda. Y si no residiere los nueve meses enteros, por cada tres dias que residiere podra tomar uno de recreaçion, y por cada tres messes podra tomar uno de recreaçion, y ansi respectiue conforme al tiempo que residiere». A.H.D.S., Fondo General, Constituciones, leg. 318 bis, fols. $7 \mathrm{v}-8 \mathrm{v}$.
} 
Canónigos. La primera referencia documental a la intención de construirlo es un acta capitular del 14 de noviembre de 1781, donde el cabildo nombra al canónigo secretario Antonio Sánchez para «demarcar el sitio para la fabrica de dichas casas» para «havitaciones de los señores capitulares» junto con el ingeniero Fernando Gaber. En el mismo documento se indica que en un principio se tenía la intención de construir nueve casas figurando como promotor de la empresa y financiador el arzobispo compostelano Francisco Alejandro Bocanegra ${ }^{64}$. Cinco años después, el 3 de octubre de 1786, los prebendados ya poseen las trazas del edificio, resolviendo que el canónigo Ramón Bernardo Pillao «pasase a Santiago... a practicar diligencias para el logro de su fabrica y... presentar dicho plano» ${ }^{65}$.

El 20 de febrero de 1792 ya han cobrado 300.000 reales del espolio de Bocanegra «para comprar y prevenir los materiales para la obra» y ya se tiene todo listo para comenzar con los trabajos. Entre las primeras decisiones estuvo la de concertar la edificación del inmueble a jornal y que «... todos y cada vno de los señores capitulares avian y podian asistir a la obra, zelar y velar... sobre los operarios, materiales y mas perteneciente a ella». Asimismo se designa al secretario José Fernández como tesorero «para custodiar los caudales y pagar los operarios, carros, maderas, cal y mas necesario a la obra» ${ }^{66}$.

Afortunadamente se conserva un legajo con parte de las cuentas de esta empresa artística desde que se comenzó a extraer piedra en la cantera el 22 de abril de 1793 hasta septiembre de 1798 , cuando ya se tenía muy avanzada la construcción ${ }^{67}$. La mayor parte de dicho legajo está compuesto por recibos y listas de operarios que trabajaron en la fábrica, el número de días que lo hicieron y sus salarios. Así, en el primer día de trabajo, la lista la integran el maestro de la obra Antonio de Soto y Acuña, el aparejador José Campañó, los canteros José Pego, José Benito Crespo, Manuel Ares, Domingo de Area, Tomás Piñeiro, Juan Benito, Ignacio de Breis, Francisco Taboada, Alonso Sotelo, Pedro Ribadulla, Teodoro García, Alberto de Castro e Ignacio García, y los peones Juan de Lema y Julián de Cruces ${ }^{68}$. Pero los nombres de canteros y peones de la lista se incrementan y fluctúan enormemente durante los cinco años documentados. A ellos se unen pronto los de los herreros que confeccionan cuñas, cinceles, martillos y otras herramientas para extraer la piedra y trabajarla, los de los carreteros que se encargan de los transportes, los de los carpinteros y serradores que cortan la madera necesaria, y los de los patrones de barcos encargados de traer cientos de fanegas de cal ${ }^{69}$.

${ }^{64}$ A.H.D.S., Fondo General, Colegiata de Iria, Libro de Actas Capitulares, leg. 328, 1781, fol. 2r.v. Sobre este arzobispo véase Pazos, M.R., op. cit., 297-305. Sobre la historia de las 9 casas véase Rodríguez González, A., «La Casa de los Canónigos de Iria Flavia», Pascoa-Padrón, 1996, Santiago, 1996, sin paginar.

65 A.H.D.S., Fondo General, Colegiata de Iria, Libro de Actas Capitulares, leg. 328, 1786, fol. 6r.v

${ }^{66}$ A.H.D.S., Fondo General, Colegiata de Iria, Libro de Actas Capitulares, leg. 328, 1792, fols. 13v.-14v. El secretario admitió el cargo pero con estas condiciones: «La $1 .{ }^{a}$ que los caudales se me avian de entregar puestos en mi casa por vn señor capitular destinado a este fin, de que daria recibo. $2 .^{a}$ que para hacer la paga de los materiales, operarios y carreteros se me avia de dar semanalmente una relacion de los carros, materiales y operarios. Que esta relacion ha de venir firmada del señor [canónigo] Carrillo o capitular que se nombrase y del maestro o aparejador que corriese con la obra. 3. ${ }^{a}$ Que la cantidad semanal de jornales y carros que dicha relacion firmada expresase la he de entregar al maestro, y este ha de pagar los carreteros y operarios sin que de mi parte haia mas que hacer que entregar al maestro la cantidad. $4 .{ }^{a} Q u e$ no he de ser responsable de casos fortuitos. 5. ${ }^{a}$ Que siempre y quando me parezca he de hacer demision del dicho oficio de tesorero, y el cavildo lo ha de admitir cargandolo a otro señor capitular».

${ }^{67}$ A.H.D.S., Fondo General, Colegiata de Iria, leg. 320, «Copias de las Relaciones que sirvieron para los pagamientos ordinarios de recivos y mas documentos de gastos extraordinarios hechos en tiempo que estubo a cargo del yllustre Cavildo de esta Santa Yglesia de Yria la obra de [las] Casas fundadas por el excelentisimo señor Don Francisco Alexandro Bocanegra y Xibaxa, Arzobispo y Señor de esta Diocesis, y construidas por cuenta de su expolio, siendo Colector general de los de este Reyno el señor Don Pedro Joaquin de Murcia, a quien se remitieron los originales en la misma forma y numero de ojas que contienen estos seis mazos, al fin de los quales se halla un rezivo de los enseres y dinero que recogieron los nueuos Comisionados que alli firman».

${ }_{68}$ A.H.D.S., Fondo General, Colegiata de Iria, leg. 320, Copias de las Relaciones..., op. cit., Mazo 1, fol. 1r.

${ }^{69}$ Por ejemplo el 9 de noviembre de 1794 el maestro de la obra seguía siendo Antonio de Soto y Acuña; el alistador, José Benito Arias; los canteros a pie de obra, Juan da Fonte, Pablo Piliteiro, Fructuoso Rodríguez, Melchor González, José 
En julio de 1794 el «alistador de la obra», José Benito Arias, solicita «se le aumentase en el sueldo de 5 reales diarios que gozaba en consideracion de su mucho trabajo. Y se le concedio el aumento de medio real» ${ }^{70}$. El 30 de julio se corta madera de castaño en el Soto de Pedrera «para las nuebe casas» ${ }^{71}$. El 2 de noviembre se pagan al maestro herrero Antonio García las primeras rejas de «las Casas de los señores canonigos» ${ }^{72}$. El 23 de junio del año siguiente se le renumeran al mismo artífice otras dos «para las claraboyas de la escalera» ${ }^{73}$. El 18 de octubre se nombra al canónigo Antonio Sánchez para «que solo con este entiendan y traten los ocupados en dicha obra» ${ }^{74}$. El 10 de abril se anuncia la compra de más de mil fanegas de cal «a cinco reales y medio cada una que conducia una embarcación procedente de Rivadeo para la construcion de las nuebe casas» ${ }^{75}$. El 20 de abril de 1796 se abonan «tres rejas para las escaleras que pesaron 571 libras» ${ }^{76}$. Más adelante, el 7 de mayo se nombra a Blas Villar como nuevo maestro director de la obra ${ }^{77}$. El 10 de junio se despide al susodicho Arias y el prebendado Sánchez renuncia a la dirección de los trabajos. En el cabildo de dicha fecha se acuerda «... que a causa de las continuas desabenencias que se notaban en los operarios de la obra y molestia entre los mismos señores capitulares, ni por entonzes ni por lo suceçibo en tiempo alguno se admitiesen por alistadores a el referido Arias ni a Gandana, y que solo el maestro entendiese en la obra abisando a el cavildo de quanto ocurra» ${ }^{78}$. A partir del 11 de septiembre llegan semanalmente carros cargados de teja de Santa Cristina de Campaña,

Nartallo, Benito García, Alonso Vilar, Gabriel Diz, Andrés Fontenla, José Magariños, Francisco Bugallo, Juan Antonio Maquieira, Ignacio Fontenla, Alberto da Fonte, Manuel Durán, Domingo Abelleira, Domingo da Silba, Ambrosio Delgado, Francisco Tato, Rosendo Durán, José Gondar, Antonio Suárez, Pedro García, José Casal, José Chan, Benito García, Manuel Bautista, Jacinto Cousido, Ramón Eyrín, José da Bua, Manuel da Fonte, José Fontanes, Pedro do Baño, Francisco de Castro, Antonio Filgueiras, Antonio Lorenzo, Antonio Cancela, Benito Gómez, José Barreiro, Miguel Piñeiro, Francisco Serviño, Antonio de Lagos, Antonio Rosende, Jerónimo Paz, Julián Parada, Juan Maquieira y José da Fonte; los peones, José Díaz, Benito de Castro, Francisco Méndez, Francisco Magán, Juan Chacón y Francisco Rodríguez; los canteros de la cantera, José Campañó, Domingo Fernández, Domingo Folgar, Gregorio de Navia, Antonio Bragaña, Ramón da Fraga, Andrés Pereira, Pedro Sayanes, Gregorio Vázquez, Juan de Albas, Francisco Pego, Felipe Martínez, José García, Miguel Nartallo, Domingo Rodríguez, Francisco de Aboy, Joaquín do Souto, Antonio Carvallo, José Vilar, Antonio Fernández, Alberto Martínez, José Tato, Juan Antonio Tato, Alberto Iglesia, Juan Blanco, Andrés Folgar, Francisco Piliteyro, José Lorenzo; los peones de la cantera, José Lorenzo, Manuel Gómez, Domingo Pardal, Domingo Sende, Francisco Gil, Francisco Pereira, Benito Lorenzo y Bartolomé Barreiro; los carreteros, Rosa Domínguez, Antonio Fontenla, Baltasar Mirazo, Juan Pérez, Juan de Barros, Benito Cristobo y Bernardo López; los carpinteros, José Pereira y Tomás Pereira; los herreros, Benito Sanmartín con el peón Roque Pereira (A.H.D.S., Fondo General, Colegiata de Iria, leg. 320, Copias de las Relaciones..., op. cit., Mazo 2..$^{\circ}$, fols. $37 \mathrm{r} .-38 \mathrm{v}$.)

70. A.H.D.S., Fondo General, Colegiata de Iria, Libro de Actas Capitulares, leg. 328, 1794, fol. 19r.

${ }^{71}$ Ibidem, 1795, fol. 22r.v.

72 A.H.D.S., Fondo General, Colegiata de Iria, leg. 320, Copias de las Relaciones..., op. cit., Mazo 2. ${ }^{\circ}$, fol. 41 r.

${ }^{73}$ Ibidem, Mazo $3 .^{\circ}$, fol. $46 \mathrm{r}$

${ }^{74}$ A.H.D.S., Fondo General, Colegiata de Iria, libro de Actas Capitulares, leg. 328, 1795, fol. 26r.v.

${ }^{75}$ Ibidem, 1795, fol. 38r.v.

${ }^{76}$ A.H.D.S., Fondo General, Colegiata de Iria, leg. 320, Copias de las Relaciones..., op. cit., Mazo 4. ${ }^{\circ}$, fols. 39v.-40r.

${ }^{77}$ Con él trabajan de aparejador, Domingo Monteagudo; de canteros, Pedro Gómez, Rosendo Durán, Ignacio Monteagudo, Sebastián Arzua, Pablo Ruibal, Gregorio Armada, Julián Martínez, Benito Anreal, Francisco Bugallo, José Tato, José de Barros, Pedro Romay, Antonio Loureiro, Eugenio da Pena, Plácido de Douto, Benito Blanco, Pedro Caeiro, José Goldar, Domingo Antonio Cancela, Andrés da Pena, Juan Villar, Baltasar Villar, Cayetano Barros, Manuel Blanco, José Antonio Baliño, José Baliño, Andrés Folgar, Andrés Campañó, Pedro Lantaño, Domingo Antonio Fontecoba, José Figueroa, Juan Bugallo, Domingo Antonio Sobral, Cayetano Fontenla y Lucas do Souto; de peones, Manuel Gómez, Juan López, Francisco da Bua, Carlos Elías, Pedro Mariño, Francisco Amecil, Toribio Ruibal, Juan Biramonte, José Santiago e Ignacio Ruibal; de maestro de carpintería, Manuel de Prabía; de carpinteros, José da Bua, Luis Maquieira, José Montaner; de herrero, Bernardo Ruibal; de aparejador de la cantera, Salvador Crespo; de canteros de la cantera, Francisco Martínez, José Gómez, Antonio Fernández, Ramón de Arca, Pedro Núñez, Juan Pereira, Antonio Costenla, Miguel Monteagudo, Felipe Meaño, Salvador Fernández, Ignacio da Silba, Urbano da Fraga; de peones de la cantera, José Lorenzo, Antonio Pardal, Antonio Martínez, José Benito Martínez; de carreteros, Tobio González, Marcos Payzal y Lorenzo Torrado (A.H.D.S., Fondo General, Colegiata de Iria, leg. 320, Copias de las Relaciones..., op. cit., Mazo 4. ${ }^{\circ}$, fols. 7r-8v.). Sobre Blas Villar véase Couselo Bouzas, J., op. cit., 654.

${ }^{78}$ A.H.D.S., Fondo General, Colegiata de Iria, Libro de Actas Capitulares, leg. 328, 1796, fol. 29r.v. 
en Valga ${ }^{79}$. El 23 de diciembre se sigue adquiriendo madera y «... se leyo un memorial por el que participaba... el maestro de canteria de las casas insinuadas que no avia en los almacenes cal para continuar la obra en la proxima temporada. Por lo que se acordo mandar venir un barco de cal» ${ }^{80}$. El 30 de junio y el 10 de noviembre de 1797 se sigue comprando made$\mathrm{ra}^{81}$. En dicho año también se obtienen nuevos fondos económicos del espolio del arzobispo Malvar, aunque parece que los trabajos se detuvieron durante algún tiempo ${ }^{82}$.

Por fin, en la reunión capitular del 10 de octubre de 1800 se expresa la intención de terminar la construcción de las casas ${ }^{83}$. El 16 de septiembre del año siguiente se envía a Santiago al canónigo secretario Ambrosio Ogando a tratar con el colector de espolios «sobre la continuación de [1] a obra de las nueve casas» ${ }^{84}$, el cual entrega el 7 de febrero de 1804 cuarenta mil reales «que era quanto podia dar, previniendo al cavildo se valiese de otros arbitrios a efecto de concluirla» ${ }^{85}$. El 10 de junio de 1805 el arquitecto académico Melchor de Prado y Mariño redacta un informe «... para reconocer si lo que está fabricado ó construido en las nuebe casas de Santa Maria de Yria se halla arreglado al diseño formado por Don Juan Lopez. Freire, y además à qüanto podra acender lo que resta todabia por executar en dichas casas hasta su entera y perfecta conclusion» ${ }^{86}$. Ilustra su escrito con un dibujo con la «distribución» correcta de cada una de las casas, que hoy se ha perdido. Pero gracias al informe nos enteramos de que el inmueble estaba prácticamente terminado en lo que se refiere a la obra en piedra, salvo la Casa 8 y la 9 , en el extremo derecho, pues «estan por concluir de paredes y por consiguiente $l e[\mathrm{~s}]$ falta todo lo demas». Al resto sólo les faltaban detalles como puertas, ventanas, suelos o bisagras y cerraduras. En total, presupuesta lo que resta por hacer en 285.329 reales y 22 maravedís. A tal cantidad hay que añadir 12.299 reales necesarios para construir el muro de las huertas con «piedra irregular y arcilla» y la acera del Camino Real «en toda la linea que cogen las casas» con un pequeño foso que evacúe el agua de las lluvias ${ }^{87}$.

En los meses siguientes se termina el inmueble con los pocos medios obtenidos ${ }^{88}$, si bien parece que queda sin construir una de las casas previstas, la más extrema del lado derecho, cuyo solar ocupa hoy un edificio moderno de un solo piso que rompe el ritmo del conjunto ${ }^{89}$. La anexión de huertas es posterior, pues los terrenos fueron adquiridos a partir de octubre de $1811^{90}$. En abril de 1815 se resuelve rodearlas de muros ${ }^{91}$.

Las llamadas Casas de los Canónigos constituyen uno de los primeros inmuebles o bloques residenciales del ámbito gallego de austeridad neoclásica. Se compone de ocho viviendas idénticas, cada una para un prebendado, que se disponen a cordel en el camino que conduce de San-

\footnotetext{
79 A.H.D.S., Fondo General, Colegiata de Iria, leg. 320, Copias de las Relaciones..., op. cit., Mazo 4. ${ }^{\circ}$, fol. $34 \mathrm{v}$. y ss.

80 A.H.D.S., Fondo General, Colegiata de Iria, Libro de Actas Capitulares, leg. 328, 1796, fol. 31 r.v.

81 Ibidem, 1797, fols. 38v. y 44r.

82 A.H.D.S., Fondo General, Colegiata de Iria, Libro de Actas Capitulares, leg. 328, fols. 42r., 43v.-44r., y 1798, fol. 49r. Sobre este prelado véase Pazos, M. R., op. cit., 306-338.

83 A.H.D.S., Fondo General, Colegiata de Iria, Libro de Actas Capitulares, leg. 328, 1800, fol. 76r.v.

${ }^{84}$ Ibidem, 1801, fol. 95r.

85 Ibidem, 1804, fol. $227 \mathrm{v}$.

${ }^{86}$ Para una visión general de la vida y obras de este artista véanse Murguía, A., El Arte en Santiago..., op. cit., 227; Couselo Bouzas, J., op. cit., 549-552; Otero Túñez, R., «Melchor de Prado y la Academia de San Fernando», Cuadernos de Estudios Gallegos, 1969, 126-139; López Vázquez, J.M., «Arte Contemporáneo», Galicia. Arte, t. XV, A Coruña, 1993, 79-83; Pérez Rodríguez, F., «Datos para las biografías de los hermanos Manuel y Melchor de Prado y Mariño», Compostellanum, 1997, 465-476.

${ }^{87}$ A.C.S., Informe de Melchor de Prado de las Casas de los Canónigos de Iria, doc. suelto.

${ }^{88}$ En julio de 1813 se compra teja para reparar sus cubiertas (A.H.D.S., Fondo General, Colegiata de Iria, Libro de Actas Capitulares, leg. 328, 1813, fol. 301r).

89 Dada la planta del mismo es probable que se levante sobre los cimientos de la antigua casa.

90 A.H.D.S., Fondo General, Colegiata de Iria, Libro de Actas Capitulares, leg. 328, 1811, fol. 293v., 1814, fols. 311r. y $316 \mathrm{v}$.

91 Ibidem, 1815, fol. 323r.v.
} 
tiago a Pontevedra, hoy Carretera General, haciendo frente a la fachada occidental de la colegiata ${ }^{92}$.

Aporto en este trabajo el descubrimiento del proyecto original del edificio que, aunque figura sin firmar encuadernado en un legajo ${ }^{93}$, por el informe de Melchor de Prado sabemos debió de ser dibujado por el arquitecto asentado en Compostela Juan López Freire ${ }^{94}$. Consta de una planta y un alzado con escala ${ }^{95}$ (figs. 12-13). La primera contiene el plan cuadrangular del bajo y el primer piso de una de las nueve casas, en concreto de una de las intermedias, dado que aparecen dibujados los arranques de los muros de las viviendas limítrofes. Algunas letras y números ayudan a la comprensión de la función de las diversas estancias. Así, en el bajo se distribuyen las cuadras y las habitaciones de almacenaje de productos agropecuarios - leñera, bodega, granero y pajar - y en la primera planta las estancias del área residencial propiamente dicha: dos salas, varios dormitorios y alcobas, un gabinete y la cocina con su correspondiente alacena. A la casa se accede por una puerta situada en el eje de la fachada. Tras ella se dispone un amplio zaguán del que arranca la escalera principal que comunica ambos niveles. Existe otra secundaria que, creo, sube al fayado. Pero aún hay otro vestíbulo en la parte de atrás con una puerta más pequeña y asimétrica que da acceso a las huertas traseras. Ambos lienzos, delantero y posterior, aparecen ampliamente horadados de ventanas, muchas de ellas cerradas por rejas, contando el primero además con dos pequeños balcones.

El alzado contiene el sobrio frente principal de las dos casas extremas de la izquierda - la Casa 1 y la 2 - que se repetiría en las otras ${ }^{96}$. Dicho frente se remata a la izquierda con un machón compuesto de grandes sillares de cantería que se supone se dispondría también en la esquina derecha del inmueble. Como se observa en el dibujo, las fachadas de ambas casas son idénticas y comparten con las otras viviendas el mismo tejado a dos aguas, el zócalo y una volada cornisa. Sus dos niveles aparecen separados por una línea de imposta corrida. El ritmo de la distribución de los vanos, de sencillo enmarque, es siempre el mismo: en el bajo se abren una puerta central y dos ventanas; en el piso superior otras dos ventanas, en eje con las citadas, y dos balcones en el centro con baranda de hierro forjado y manzanas en las esquinas.

Si comparamos los dibujos con lo finalmente construido se descubren varias diferencias (fig. 14): así lo observó también Melchor de Prado cuando escribió en su ya citado informe que «aunque se nota alguna diferencia entre la distribucion de... [las casas] y en el dibujo, nobstante en lo general no es mui sensible». Así, la disposición interior de las casas no sigue a rajatabla la concebida en un primer momento, si bien hay que tener en cuenta la posibilidad que haya habido alguna reforma desde entonces. Por ejemplo, la escalera de piedra de cada casa se dispone en su eje, tras el zaguán. La cocina, en cambio, se encuentra en el ángulo noroccidental, contando con una espectacular lareira cuya campana pétrea se apoya en un delgadísimo pilar. Su peso, junto con el del suelo, también de piedra por el peligro de incendios, motiva que la sala dispuesta debajo presente dos arcos sostenedores.

\footnotetext{
${ }_{92}$ Tengo noticia de que se proyecta peatonalizar el tramo de Iria y desviar por otro recorrido la carretera.

93 A.H.D.S., Fondo General, Colegiata de Iria, leg. 319, fols. 8v. y 9r.

94 Para una visión general de la biografía y obras de este artífice véanse Murguía, M., El Arte en Santiago..., op. cit., 218219; Couselo Bouzas, J., op. cit., 426- 429; López Vázquez, J.M., op. cit., 76-77.

${ }_{95}$ La planta presenta las siguientes notas manuscritas: «Plan Terreno. Distribución y destino de las piezas del Plan Terreno: A, Portal o Zaguan; B, Escalera; C, Bodega; D, Granero; E, leñera; F, Dispensa; G, Cavalleriza; H, Portal de parte de Mediodia; I, Paxar» y "Plan Alto. Distribuzion y destino de las piezas del Plan Alto: 1, Salas; 2, Quartos; 3, Alcobas; 4, Quarto del criado; 5, Alcova de la criada; 6, Cozina; 7, Dispensa; 8, Gavinete; 9, Alcova; 10, Escalera; X, Alazena». Y el alzado la leyenda siguiente: «Regla mensuraria de varas castellanas».

96 Tal dibujo corresponde a la casa que hoy ocupa la Fundación Camilo José Cela y a su vecina de propiedad particular. En cuanto al resto de las viviendas, la Casa 4, la 5 y la 8 pertenecen también a la Fundación, la Casa 3 es de propiedad eclesiástica, y la Casa 6 y la 7 son particulares.
} 

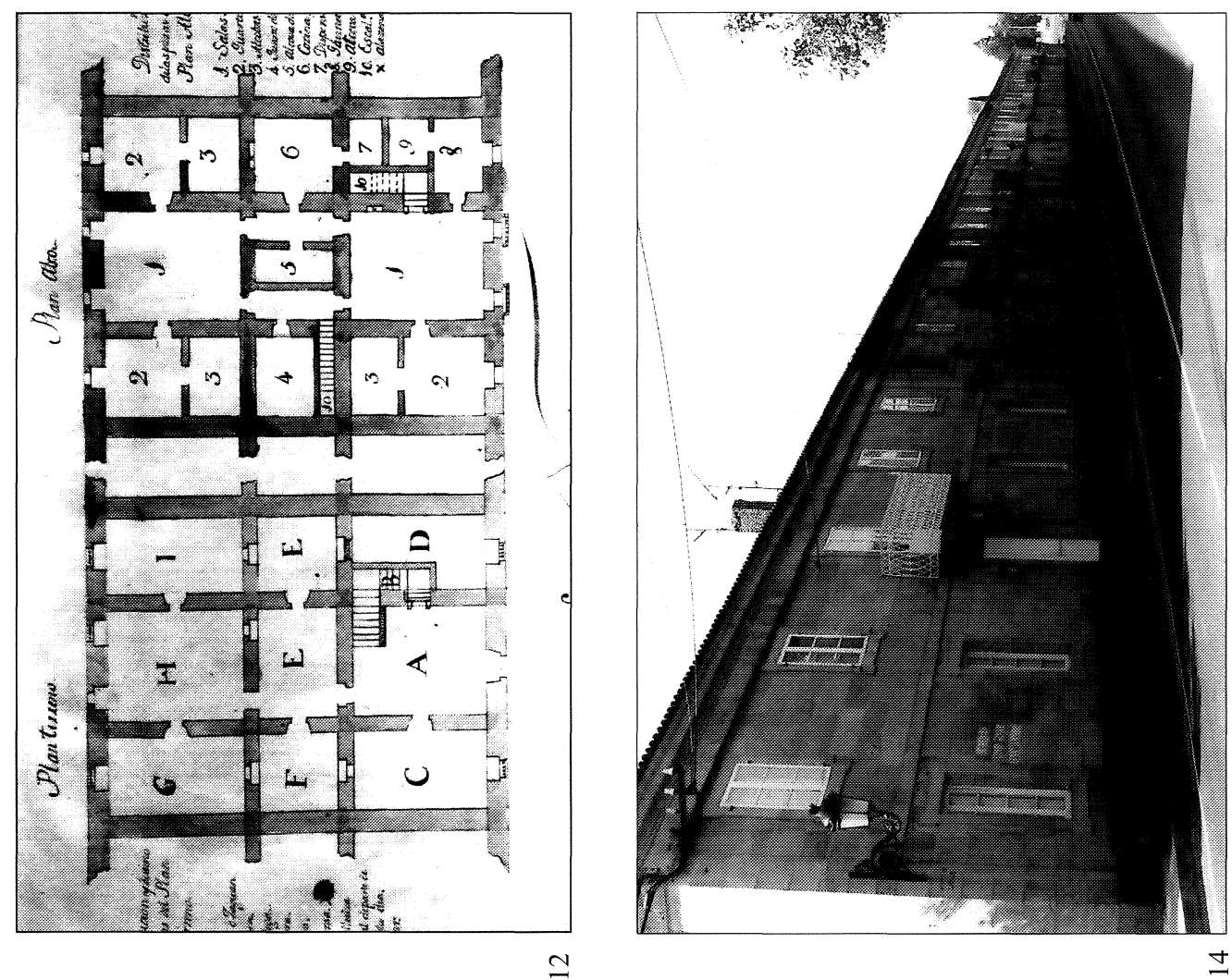

$\simeq$

n

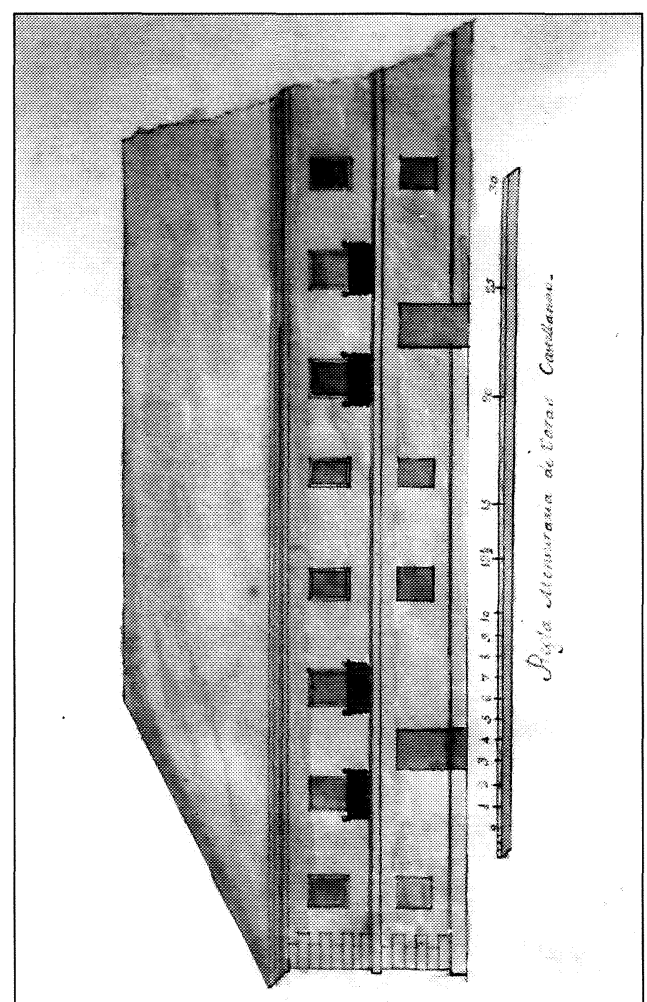

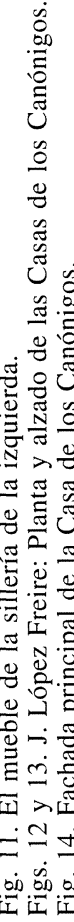

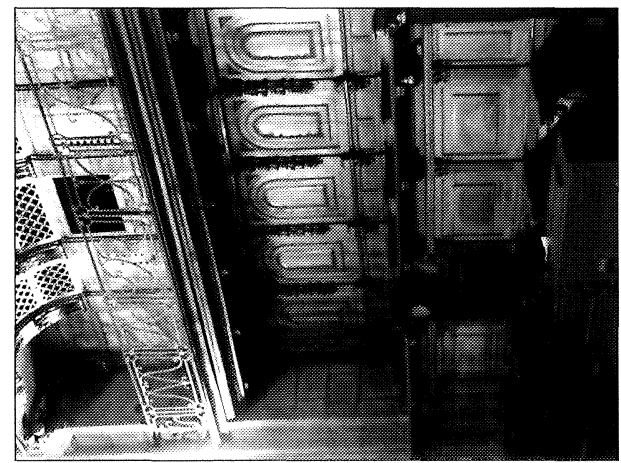


En cuanto a la fachada del edificio, construida con sillares de buena estereotomía, los principales cambios son la separación de cada una de las viviendas con machones apilastrados y la distribución de los vanos de grueso enmarque acodado: en la planta baja se abren cuatro aberturas en torno a la puerta - tragaluces enrejados en las Casas 3, 4 y 5, y amplios ventanales rectangulares en las restantes - y en la planta superior cuatro ventanas, en línea con los anteriores, y un solo balcón de baranda de hierro, en este caso en eje sobre el acceso. Hacia la parte de atrás se abre una puerta, pues cada vivienda cuenta aún hoy con una huerta-jardín perfectamente delimitada por un pequeño paredón. Hacia ellas da el frente trasero, construido con mampostería enlucida, que, como se observa en el dibujo, no cuenta con ninguna solana, consistiendo en un sencillo muro corrido perforado con ventanas sobre el que se levantan ocho monumentales chimeneas, una por casa.

La Casa 5 corona su fachada del camino con una peineta semicircular que contiene una placa pétrea destinada a un escudo del cabildo o de uno de los prelados patrocinadores que nunca se llegó a tallar. Si se conservase la prevista Casa 9, tal remate quedaría como eje del conjunto.

Como ya se ha dicho, la Casa de los Canónigos de Iria es uno de los primeros bloques residenciales de Galicia, cuya antigüedad es superada por la Casa de la Conga en la Plaza de la Quintana en Santiago, compuesta por dos viviendas destinadas también a canónigos y construida en las dos primeras décadas del siglo XVIII ${ }^{97}$. Y es en la arquitectura doméstica coetánea de Compostela, particularmente la debida a trazas de Miguel Ferro Caaveiro y a las del propio López Freire, donde se encuentran las pautas seguidas por el autor del edificio iriense con cuyas fórmulas comulga tanto en la distribución interior como en la disposición de la fachada: ambos autores se caracterizan por delimitar los frentes de sus casas con machones o pilastrones toscanos, separando cada piso con un listel corrido y enmarcando cada uno de los vanos con abultados alfices. Al respecto, resultan ilustrativos edificios residenciales como el n.$^{\circ} 2$ de la Rúa de la Azabachería, el n. ${ }^{\circ}$ 21-23 de la Algalia de Abaixo, el n. 9 de la Calle de San Roque, el n. ${ }^{\circ} 10$ de Entremuros, entre otros ${ }^{98}$.

Con la construcción de la colegiata y del inmueble se reordena urbanísticamente la zona. De hecho, en el contrato firmado en 1712 por Pedro García se compromete a que «la parte de afuera de dicha yglessia» ha de quedar empedrada, particularmente en «la delantera» ${ }^{99}$. Entre 1764 y 1765 se construyen el muro que rodea el atrio de la colegiata y su cementerio ${ }^{100}$, las «piramides» coronadas con una bola que lo recorren, sus tres entradas, una al norte haciendo frente a las Casas de los Canónigos, otra al sur y una tercera al este - estas últimas abiertas hacia el burgo de Iria- y las puertas enrejadas que las cerraban ${ }^{101}$. Tal cierre mural aún fue reformado posteriormente con la construcción del actual parapeto en el frente del templo, jalonado de jarroncetes gallonados.

\footnotetext{
${ }^{97}$ Cfr. Taín Guzmán, M., Domingo de Andrade..., op. cit., vol. I, 319-330.

98 Sobre el tema véanse Ortega Romero, M. ${ }^{a}$ del S., «El arquitecto Miguel Ferro Caaveiro», Cuadernos de Estudios Gallegos, 1970, 143-164; Ríos Miramontes, M. ${ }^{a}$ T., «Miguel Ferro Caaveiro: el caserío compostelano», Cuadernos de Estudios Gallegos, 1974-75, 165-176; López Vázquez, J. M., op. cit., 76-77.

99 A.H.U.S., Sección Protocolos de Padrón, leg. 3.405, Fco. Buceta Señoráns, 1712, fol. 5r.

100 Tal atrio y cementerio fueron excavados por Chamoso Lamas en 1962 encontrando en ellos abundante material arqueológico de época romana y medieval. Cfr. Chamoso Lamas, M., Iria Flavia..., op. cit., 43.

101 A.H.D.S., Fondo General, Colegiata de Iria, leg. 319, fol. 512v. En 1786 aún se vuelve a intervenir en el atrio, si bien desconozco el nivel de la operación (A.H.D.S., Fondo General, Colegiata de Iria, Libro de Actas Capitulares, leg. 328, 1781, fol. 6r.)
} 